\title{
Breast Cancer Resistance Protein and Multidrug Resistance Protein 2 Determine the Disposition of Esculetin-7-0-Glucuronide and 4-Methylesculetin-7-O-Glucuronide
}

\author{
Yuhuan Li, ${ }^{1}$ Wenjie Song, ${ }^{1}$ Xiaojun Ou, Guangkuo Luo, Yushan Xie, Rongjin Sun, Ying Wang, \\ Xiaoxiao Qi, Ming Hu, Zhongqiu Liu, and Lijun Zhu
}

Joint Laboratory for Translational Cancer Research of Chinese Medicine of the Ministry of Education of the People's Republic of China, International Institute for Translational Chinese Medicine, Guangzhou University of Chinese Medicine, Guangzhou, Guangdong, People's Republic of China (Y.L., W.S., X.O., G.L., Y.X., R.S., Y.W., X.Q., M.H., Z.L., L.Z.); State Key Laboratory of Quality Research in Chinese Medicine, Macau University of Science and Technology, Macau (Special Administration Region), People's Republic of China (Z.L.); and Department of Pharmacological and Pharmaceutical Sciences, College of Pharmacy, University of Houston, Houston, Texas (M.H.)

Received July 7, 2018; accepted December 27, 2018

\begin{abstract}
Esculetin (ET)-7-O-glucuronide (ET-G) and 4-methylesculetin (4-ME)-7-O-glucuronide (4-ME-G) are the main glucuronide of ET and 4-ME, respectively. The disposition mediated by efflux transporters for glucuronide has significant influence on the pharmacokinetic profile and efficacy of bioactive compounds. In the current study, transporter gene knockout mice and Caco-2 cells were used to explore the effects of breast cancer resistance protein (BCRP) and multidrug resistance-associated protein 2 (MRP2) on the disposition of ET-G and 4-ME-G. After oral or i.v. administration of ET and 4-ME, the area under the plasma concentration-time curve from time 0 to the last data point or infinity values of ET, 4-ME, and their glucuronides (ET-G and 4-ME-G) were remarkably and significantly increased in most $\mathrm{Bcrp}^{-/-}$and $\mathrm{Mrp2}^{-/-}$mice compared with those in wild-type FVB mice $(P<0.05)$. These results were
\end{abstract}

accompanied with a significant increase of maximum plasma concentration values $(P<0.05)$. In Caco-2 monolayers, the efflux and clearance rates of ET-G and 4-ME-G were markedly reduced by the BCRP inhibitor Ko143 and MRP2 inhibitor MK571 on the apical side $(P<0.05)$. In an intestinal perfusion study, the excretion of ET-G was significantly decreased in perfusate and increased in plasma in $\mathrm{Bcrp1}^{-1-}$ mice compared with those in wild-type FVB mice $(P<0.05)$. The 4-ME-G concentration was also decreased in the bile in transporter gene knockout mice. ET and 4-ME showed good permeability in both Caco-2 monolayers [apparent permeability $\left.\left(P_{\text {app }}\right) \geq 0.59 \times 10^{-5} \mathrm{~cm} / \mathrm{s}\right]$ and duodenum $\left(P_{\text {app }} \geq 1.81\right)$. In conclusion, BCRP and MRP2 are involved in excreting ET-G and 4-ME-G. ET and 4-ME are most likely absorbed via passive diffusion in the intestines.

\section{Introduction}

Esculetin [6,7-dihydroxy-coumarin (ET)] is a well-known naturally occurring coumarin derivate found in many herbs, such as Fraxinus rhynchophylla, Rehmanniae glutinosa, and Artemisia capillaries (Li et al., 2011; Venugopala et al., 2013). ET provides a broad range of

\footnotetext{
${ }^{1}$ Y.L. and W.S. contributed equally to this work.
}

This work was supported by the projects of National Natural Science Foundation of China [Grants 81603379, 81874343, and 81720108033], Pearl River Nova Program of Guangzhou [Grant 201806010199], Natural Science Foundation of Guangdong Province [Grants 2015A030312012 and 2015B020233015], and Guangdong Province Universities and Colleges Pearl River Scholar Funded Scheme (2015).

There is no financial conflict of interests with the authors of this paper. Publication of this paper will not benefit or adversely affect the financial situations of the authors.

https://doi.org/10.1124/dmd.118.083493. pharmacological activities, including antioxidant, anti-inflammatory, antitumor, antiviral, antifungal, and neuroprotective properties (Witaicenis et al., 2010; Vianna et al., 2012; Wang et al., 2012; Jeon et al., 2015). The 4-methylesculetin [6,7-dihydroxy-4-methylcoumarin (4-ME)], a synthetic coumarin derivate that contains a methyl group at C-4 in ET molecules, has also been extensively investigated because it exhibits various pharmacological functions similar to those of ET (Hajime et al., 2007; Hemshekhar et al., 2013; Maistro et al., 2015). Thus, ET and 4-ME, as potential therapeutic agents, have attracted substantial attention from researchers.

The disposition characteristics of bioactive compounds influence their in vivo pharmacokinetics and pharmacodynamics. Elucidation of the disposition characteristics and underlying mechanisms of the disposition of these compounds would provide information to identify potential drug candidates and drug-drug interactions. We have previously demonstrated that the conjugation reactions of ET and 4-ME at the 7-C position generate ET-7-O-glucuronide (ET-G) and 4-ME-7$\mathrm{O}$-glucuronide (4-ME-G), respectively. This reaction is mediated by

ABBREVIATIONS: 4-ME, 4-methylesculetin; 4-ME-G, 4-ME-7-O-glucuronide; AP, apical; AUC, area under the plasma concentration-time curve; $\mathrm{BCRP}$, breast cancer resistance protein; BL, basolateral; $\mathrm{C}_{\max }$, maximum plasma concentration; $C L$, clearance; ET, esculetin; ET-G, ET-7-Oglucuronide; $\overline{F \%}$, bioavailability; $F_{\text {met }}$, fraction of the metabolized dose; HBSS, Hanks' balanced salt solution; IS, internal standard; $J$, efflux rate; M/P, Metabolite/Parent; MRP, multidrug resistance-associated protein; $P_{\text {app }}$, apparent permeability; $P^{\star}$ eff, effective intestinal permeability; UHPLCMS/MS, ultrahigh-performance liquid chromatography-tandem mass spectrometry. 
UDP-glucuronosyltransferase 1A9 and UGT1A6 in human liver and intestinal microsomes (Zhu et al., 2015). The elimination of glucuronides from cells requires the aid of efflux transporters [e.g., breast cancer resistance protein (BCRP)] because these metabolites are too hydrophilic to diffuse across the cellular membrane (Jeong et al., 2005b; Wang et al., 2006). The clinical evidence of impaired BCRP activity produced increased systemic exposure of gefitinib, rosuvastatin, sunitinib, and active metabolite of leflunomide, sulfasalazine, and diflomotecan (Lee et al., 2015). The importance of efflux transporters modulating the glucuronides excretion of bioactive compounds has been demonstrated in wild-type and transporter knockout mice (Ge et al., 2015; Qin et al., 2018). Thus, further investigation into the role of efflux transporters in the excretion of ET-G and 4-ME-G is important to accurately predict their disposition and efficacy in vivo.

BCRP and multidrug resistance-associated protein (MRP)2 are ATPbinding cassette transporters that are widely located on the apical (AP) portions of the liver and intestine (Yang et al., 2017). BCRP and MRP2 are likely to excrete compounds with high hydrophilicity such as most conjugation metabolites (glucuronides and sulfates) (An and Morris, 2011; Zheng et al., 2016). The inhibition or deficiency of BCRP and MRP2 decreases the plasma exposure of parent drugs and their metabolites, which could result in reduced efficacy, although these drugs have good absorption characteristics (Pan et al., 2015; Kong et al., 2016). Transporter (e.g., P-glycoprotein, BCRP, and MRP2) gene knockout models, in which glucuronidation activities remain unaltered, are commonly used in understanding transporter-limited or transportermediated drug absorption, distribution, and excretion (Klaassen and $\mathrm{Lu}$, 2008; Zamek-Gliszczynski et al., 2012, 2013). Mouse Bcrp1 protein and human BCRP protein are structurally and functionally similar. They share $87 \%$ sequence homology and efflux identical substrates (Natarajan et al., 2011). Murine in vivo models harboring Bcrp1 gene knockouts in FVB or C57BL/6J mouse strains are commonly used to predict the $\mathrm{BCRP}$ regulation of human small intestinal drug disposition (Zhou et al., 2002; Agarwal et al., 2012; Jiang et al., 2017). The amino acid sequence identity of human MRP2 with its mouse ortholog is approximately $78 \%$, and Mrp2 knockout mice are frequently used to investigate the impact of MRP2 on the pharmacokinetics of clinical drugs (Zimmermann et al., 2008).

Caco-2 cells, which express various phase I and phase II enzymes as well as ATP-binding cassette transport proteins such as P-glycoprotein, BCRP, and MRPs (e.g., MRP1, MRP2, MRP3, and MRP4), are frequently used to study human intestinal absorption, metabolism, and transport (Ikeda et al., 2008; Meinl et al., 2008; Ming and Thakker, 2010). Inhibition assays in Caco- 2 monolayers are also commonly used to identify transporter substrates. Ko143 (at concentrations from 0.5 to $10 \mu \mathrm{M}$ ) and MK571 (at concentrations from 10 to $100 \mu \mathrm{M}$ ) are frequently used to confirm the role of BCRP and MRPs [including MRP2 expressed on the AP membrane and MRP3 and MRP4 expressed on the basolateral (BL) membrane] in the disposition of xenobiotics in previous studies (Sheng et al., 2015; Shi et al., 2016; Ma et al., 2017; Zang et al., 2018).

In the current study, the pharmacokinetics of ET and 4-ME in Bcrp1 and Mrp2 knockout mice, as well as that in wild-type FVB mice, was studied. Inhibition assays in Caco-2 monolayers were conducted to verify the role of BCRP and MRP2 in the disposition of ET-G and 4-ME-G in vitro. The absorption characteristics of ET and 4-ME were also evaluated in Caco-2 cells. The perfused transporter knockout mice intestinal model was employed to confirm the role of BCRP and MRP2 in the disposition of ET and 4-ME. The concentrations of ET, 4-ME, and their glucuronides in different samples, such as plasma, cell culture medium, perfusate, and bile, were determined by ultrahigh-performance liquid chromatography-tandem mass spectrometry (UHPLC-MS/MS).

\section{Materials and Methods}

Chemicals and Reagents. ET, 4-ME, ET-G, and 4-ME-G were obtained, as described previously (Zhu et al., 2015). Testosterone [used as internal standard (IS); purity >98\%], Ko143, MK571, and Hanks' balanced salt solution (HBSS; powder form) were purchased from Sigma-Aldrich (St. Louis, MO). Six-well polycarbonate cell culture inserts (with an absorption surface area of approximately $4.2 \mathrm{~cm}^{2}$ and a pore size of $3 \mu \mathrm{m}$ ) were obtained from Corning (Corning, NY). Cloned Caco-2 cells (TC7) were provided by M.H. (Department of Pharmaceutical Sciences, College of Pharmacy, University of Houston, TX). All other chemicals and solvents were of analytical grade or better.

Animals. Male wild-type FVB mice (9-11 weeks) were purchased from Vital River Laboratory Animal Technology (Beijing, China). Male Bcrp1 ${ }^{-/-}$mice and $\mathrm{Mrp}^{-/-}$mice (9-11 weeks old) of a $>99 \%$ FVB genetic background were purchased from Biomodel Organism Science \& Technology Development (Shanghai, China). Mice were kept in an environmentally controlled room (temperature of $25 \pm 2{ }^{\circ} \mathrm{C}$, relative humidity of $50 \% \pm 5 \%$, and 12-hour dark/light cycle) for at least 1 week before the experiment. The animal experiments used in this study were approved by the Guangzhou University of Chinese Medicine's Ethics Committee.

Cell Culture. Caco-2 cells were cultured in Dulbecco's modified Eagle's medium containing $10 \%$ fetal bovine serum, $1 \%$ nonessential amino acids, $1 \%$ L-glutamine, and $1 \%$ antibiotics (penicillin and streptomycin) at $37^{\circ} \mathrm{C}$ with $5 \%$ $\mathrm{CO}_{2}$. For the transport experiments, $2.5 \times 10^{5}$ cells/well were seeded onto the $4.2-\mathrm{cm}^{2}$ inserts and grown for 19-22 days. Transepithelial electrical resistance values less than $460 \Omega / \mathrm{cm}^{2}$ were discarded.

UHPLC-MS/MS Conditions. ET, 4-ME, and their glucuronides (ET-G and 4-ME-G) were separated and quantified using an Agilent UHPLC 1290 InfiniteTriple Quad MS 6460 (UHPLC-MS/MS) equipped with an electrospray ionization source. The chromatographic separation was achieved on a Zorbax $\mathrm{C}_{18}$ column $\left(100 \times 3.0 \mathrm{~mm}^{2}, 1.8 \mu \mathrm{m}\right.$; Agilent Technologies, Santa Clara, CA) using a mixture of $0.1 \%$ formic acid aqueous solution (A) and methanol (B) as the mobile phase with the following gradient elution: $20 \%(\mathrm{v} / \mathrm{v}) \mathrm{B}$ from 0 to 1 minute; $90 \%$ B from 3 to 6 minutes; $20 \%$ B at 7 minutes; and the post-time was 0.5 minutes. The injection volume was $5 \mu \mathrm{l}$, the flow rate was $0.3 \mathrm{ml} / \mathrm{min}$, and the column temperature was maintained at $35^{\circ} \mathrm{C}$. The mass spectrometer parameters were as follows: capillary voltage, $4.0 \mathrm{kV}$; nozzle voltage, $500 \mathrm{~V}$; nebulizer, $45 \mathrm{psi}$; gas temperature, $300^{\circ} \mathrm{C}$ with a gas flow of $51 / \mathrm{min}$; and sheath temperature, $350^{\circ} \mathrm{C}$ with a sheath gas flow of $11 \mathrm{l} / \mathrm{min}$.

The optimized fragmentation voltages of ET, ET-G, and testosterone (IS) were 90,100 , and $120 \mathrm{~V}$, respectively. Quantification was performed in positive ion and multiple reaction monitoring mode using the following transitions: $\mathrm{m} / \mathrm{z}$ $179.0 \rightarrow 122.9$ for ET with a collision energy of $22 \mathrm{eV} ; \mathrm{m} / \mathrm{z} 355.0 \rightarrow 179.0$ for ET-G with a collision energy of $15 \mathrm{eV}$; and $\mathrm{m} / \mathrm{z} 289.0 \rightarrow 97.1$ for testosterone with a collision energy of $22 \mathrm{eV}$. The $\delta$ electron multiplier voltage was $250 \mathrm{~V}$, and the cell acceleration voltage of all was $4 \mathrm{~V}$. The method was to waste before 1 minute, then to mass spectrometer.

The optimized fragmentation voltages of 4-ME, 4-ME-G, and testosterone (IS) were 105,135 , and $120 \mathrm{~V}$, respectively. Quantification was performed in positive ion and multiple reaction monitoring mode using the following transitions: $\mathrm{m} / \mathrm{z}$ $193.0 \rightarrow 147.0$ for 4-ME with a collision energy of $20 \mathrm{eV}$; m/z $369.0 \rightarrow 193.0$ for 4-ME-G with a collision energy of $20 \mathrm{eV}$; and $\mathrm{m} / \mathrm{z} 289.0 \rightarrow 97.1$ for testosterone with a collision energy of $22 \mathrm{eV}$. The $\delta$ electron multiplier voltage was $400 \mathrm{~V}$, and the cell acceleration voltage of all was $4 \mathrm{~V}$. The method was to waste before 2 minutes, then to mass spectrometer.

Pharmacokinetic Studies of ET and 4-ME in Wild-Type, Bcrp1 ${ }^{-/-}$, and Mrp2 $^{-/-}$FVB Mice. Mice were fasted for 10 to 12 hours with free access to water before the pharmacokinetics experiments. For oral administration, ET and 4-ME suspensions $(1 \mathrm{mg} / \mathrm{ml}$ ) were prepared with $20 \%(\mathrm{w} / \mathrm{v})$ hydroxypropyl $\beta$-cyclodextrin aqueous solution. Wild-type and transporter knockout FVB mice were orally administered with $10 \mathrm{mg} / \mathrm{kg}$ ET $(56.14 \mu \mathrm{mol} / \mathrm{kg})$ or $4-\mathrm{ME}$ $(52.03 \mu \mathrm{mol} / \mathrm{kg})$. For i.v. injection, ET and 4-ME solutions $(0.3 \mathrm{mg} / \mathrm{ml})$ were prepared with $5 \%(\mathrm{w} / \mathrm{v})$ hydroxypropyl $\beta$-cyclodextrin aqueous solution. Wildtype and transporter knockout FVB mice were i.v. injected with $2 \mathrm{mg} / \mathrm{kg}$ ET $(11.23 \mu \mathrm{mol} / \mathrm{kg})$ and $4-\mathrm{ME}(10.41 \mu \mathrm{mol} / \mathrm{kg})$. Blood samples (approximately $25 \mu \mathrm{l})$ were collected from the tail vein and then placed in dried heparinized tubes at $0,3,5,10,15,30,45,60,120,240,360,480,720$, and 1440 minutes. The first blood sample was collected by cutting the tail; the following blood samples were collected by scraping the cut. The blood samples were centrifuged at $11,040 \mathrm{~g}$ for 
8 minutes. The plasma supernatant was removed to a new tube and stored at $-80^{\circ} \mathrm{C}$ until analysis. Plasma samples were prepared by mixing $10 \mu \mathrm{l}$ plasma sample and $200 \mu \mathrm{l}$ methanol containing $200 \mathrm{nM}$ IS, followed by vortexing for 3 minutes. The mixture was centrifuged at $19,357 \mathrm{~g}$ for 30 minutes. Supernatant $(160 \mu \mathrm{l})$ was transferred to a new tube and evaporated to dryness in a vacuum drying oven. The residue was dissolved with $80 \mu 150 \%$ methanol aqueous solution. After centrifugation at $19,357 \mathrm{~g}$ for 30 minutes, $10 \mu \mathrm{l}$ supernatant was injected into the UHPLC-MS/MS for analysis.

The pharmacokinetic parameters, including area under the plasma concentration-time curve (AUC) from time 0 to the last data point or infinity $\left(\mathrm{AUC}_{0-\mathrm{t}}\right.$ and $\left.\mathrm{AUC}_{0-\infty}\right)$, half-life, maximum plasma concentration $\left(\mathrm{C}_{\max }\right)$, mean residence time, $\mathrm{V}_{\mathrm{d}}$, and clearance $(C L)$, were analyzed using the noncompartmental model in WinNonlin 3.3 (Pharsight, Mountain View, CA). The $\mathrm{AUC}_{0-\mathrm{t}}$ or $\mathrm{AUC}_{0-\infty}$ was calculated by the trapezoidal rule-extrapolation method. The average absolute bioavailability $(\overline{F \%})$ values of ET and 4-ME were determined by using the following formula:

$$
\overline{F \%}=\frac{\overline{A U C}_{0-\infty, \text { p.o. }} \times D_{\text {i.v. }}}{\overline{A U C}_{0-\infty, i . v .} \times D_{\text {p.o. }}} \times 100 \%
$$

where $\overline{A U C}_{0-\infty, p . o .}$ and $\overline{A U C}_{0-\infty, i . v .}$ represent the average of area under the concentration-time curve from zero to infinity after ET (or 4-ME) oral and injection administration, respectively. $D_{p . o}$ and $D_{i . v .}$ represent the dose of ET (or 4-ME) oral and injection administration, respectively.

Bidirectional Transport Study of ET and 4-ME in Caco-2 Monolayers. The transport experiments were conducted, as described previously (Ye et al., 2013). Before the experiment, Caco-2 monolayers were washed thrice with warm HBSS at $37^{\circ} \mathrm{C}$. Testing compound ( $2 \mathrm{ml} ; 10 \mu \mathrm{M}$ ET or 4-ME) was loaded on the AP side or BL side of the cell monolayers, and $2 \mathrm{ml}$ blank HBSS was loaded on the other side. In the inhibition experiment, BCRP inhibitor (Ko143, $5 \mu \mathrm{M})$ and MRP2 inhibitor (MK571, $10 \mu \mathrm{M}$ ) were added to the AP side to determine whether AP efflux transporters (BCRP and MRP2) participate in the efflux of ET, 4-ME, and their glucuronides. Samples $(0.5 \mathrm{ml})$ were collected from both sides of each transwell at designated times ( $0,0.5,1,1.5$, and 2 hours), and the same volume of the testing compound or blank HBSS was immediately replenished. Then $250 \mu \mathrm{l}$ methanol containing $200 \mathrm{nM}$ IS was added to $500 \mu \mathrm{l}$ incubation samples to determine the analytes. Cell monolayers were carefully washed thrice and collected into $0.3 \mathrm{ml}$ HBSS at the end of the transport experiment. Cells were ultrasonicated in an ice bath $\left(4^{\circ} \mathrm{C}\right)$ for 30 minutes. After centrifugation at $17,949 \mathrm{~g}$ for 30 minutes, the supernatant was separated into two aliquots, as follows: one was for measuring protein; the other was prepared for determining cellular ET, 4-ME, and their glucuronides. All prepared samples were centrifuged at $17,949 g$ for 30 minutes and injected into the UHPLC-MS/MS.

The apparent permeability $\left(P_{a p p}\right)$ coefficient of ET and 4-ME across a cellular membrane was estimated using the following equation:

$$
P_{a p p}=\frac{d Q / d t}{A C_{0}}
$$

where $d Q / d t$ is the rate of ET and 4-ME transported on the receiver side; $C_{0}$ is the initial concentration of compounds on the donor side; and $A$ is the monolayer growth surface area of $4.2 \mathrm{~cm}^{2}$.

The fraction of the metabolized dose $\left(F_{m e t}\right)$ was calculated in this study in response to the extent of metabolism in Caco- 2 cells by the following equation:

$$
F_{\text {met }}=\frac{\sum \text { metabolite }}{\sum \text { metabolite }+\sum \text { parent compound }}
$$

The efflux rate $(J)$ of glucuronide was obtained from the rate of change in the concentration of the substrate (or its metabolite), and this parameter was expressed as a function of time and volume of the sampling chamber $(V)$, as follows:

$$
J=\frac{d C}{d t} \times V
$$

The $C L$ of efflux transporter was calculated in this study because the extracellular concentration of glucuronides differed from their intracellular concentration. $C L$ was determined using the excretion rate of glucuronides $(J)$ divided by the intracellular concentration of glucuronides $\left(C_{\mathrm{in}}\right)$, as follows:

$$
C L=\frac{J}{C_{i n}}=\frac{J_{\max }}{K_{m}+C_{i n}}
$$

where $J_{\max }$ is the maximal excretion rate of glucuronides, and $K_{\mathrm{m}}$ is the Michaelis constant of glucuronide efflux. To determine $C_{\text {in }}$, we assumed that the average cytosolic water volume of the cells was $4 \mu \mathrm{l} / \mathrm{mg}$ protein. The intracellular metabolite concentration was calculated from the total amount of intracellular glucuronides divided by the total volume of intracellular protein.

Perfused Mice Intestinal Model for Glucuronidation Disposition of ET and 4-ME. Two segments (upper small intestine and colon) of the mouse intestine were perfused simultaneously with perfusate containing $70 \mu \mathrm{M}$ ET (or 4-ME) using an infusion pump (model PHD2000; Harvard Apparatus, Cambridge, MA) at a flow rate of $0.167 \mathrm{ml} / \mathrm{min}$. Before the surgery, each mouse was anesthetized with $10 \mathrm{mg} / \mathrm{ml}$ urethane $(0.03 \mathrm{ml} / 10 \mathrm{~g}$, i.p.). The mouse intestinal surgical procedures were modified from the rat model previously described (Chen et al., 2003; Jeong et al., 2005a). Briefly, after the mouse was anesthetized, it was put over a heating blanket and under a heating lamp to keep its normal body temperature. Then the mouse abdominal cavity was opened and the duodenum was located as the intestinal segment immediately adjacent to the stomach. First, two cannulae at approximately $10 \mathrm{~cm}$ apart were inserted into two ends of the duodenum and secured with suture. Second, the colon inlet cannula was inserted into the colon at approximately $2 \mathrm{~cm}$ below the junction, and the outlet cannula was inserted through the anus. After a 30-minute washout period, which is considered to achieve steady-state absorption, perfusate were collected from the outlet cannula every 15 minutes during the 1 -hour perfusion period. Perfusate that did not cross the intestinal segments was also collected every 30 minutes as a control. The blood samples were withdrawn from tail vein at the end of the perfusion. The gallbladder was excised, and the bile was collected. The length of the intestine was measured, as described previously (Hu et al., 1998). The effective intestinal permeability $\left(P^{*}\right.$ eff $)$ coefficient and absorption amounts of ET and 4-ME and the percentage of glucuronides (ET-G and 4-ME-G) excreted into the perfusate in the mice were measured and calculated, as described previously (Chen et al., 2003; Dai et al., 2015). The exposure of ET-G and 4-ME-G was determined by using the peak area in the perfusion experiment because the commercial source of ET-G and 4-ME-G was unavailable.

Statistical Analysis. SPSS 17.0 was used to evaluate significant differences, and unpaired Student's $t$ test was used to analyze the data. Data were presented as the mean \pm S.D. Differences were considered significant at $P<0.05$.

\section{Results}

Pharmacokinetic Profile of ET and 4-ME in Wild-Type, Bcrp1 ${ }^{-/-}$, and Mrp2 $^{-1-}$ FVB Mice. The mean plasma concentration-time curves after the oral administration of $10 \mathrm{mg} / \mathrm{kg}(56.14 \mu \mathrm{mol} / \mathrm{kg})$ ET in wildtype, Bcrp1 ${ }^{-/-}$, and Mrp2 $2^{-/-}$FVB mice are shown in Fig. 1, A and B, and the pharmacokinetic parameters are shown in Table 1. After oral administration, ET was quickly absorbed and metabolized into ET-G, and lower ET was detected in plasma samples. The $\mathrm{AUC}_{0-\infty}$ values of ET and ET-G in wild-type FVB mice were $2.96 \pm 0.98$ and $306.68 \pm$ 113.93 minutes $\bullet \mu \mathrm{mol} / \mathrm{l}$, respectively, and those in $\mathrm{Bcrp} 1^{-/-}$mice were significantly increased to $32.68 \pm 14.49$ and $1356.30 \pm$ 666.51 minutes $\bullet \mu \mathrm{mol} / 1$, respectively $(P<0.05)$. The $\mathrm{AUC}_{0-\infty}$ value of ET was significantly increased from $2.96 \pm 0.98$ minutes $\bullet \mu \mathrm{mol} / \mathrm{l}$ in wild-type FVB mice to $23.48 \pm 9.96$ minutes $\bullet \mu \mathrm{mol} / 1$ in $\mathrm{Mrp} 2^{-/-}$mice $(P<0.05)$. The $\mathrm{C}_{\max }$ values of ET and ET-G were also increased from $0.20 \pm 0.11 \mu \mathrm{mol} / 1$ in wild-type FVB mice to $8.21 \pm 5.78 \mu \mathrm{mol} / 1$ in $\mathrm{Bcrp}^{-/-}$mice for ET and $2.46 \pm 0.36 \mu \mathrm{mol} / \mathrm{l}$ in wild-type FVB mice to $7.58 \pm 1.65 \mu \mathrm{mol} / \mathrm{l}$ for ET-G in Bcrp $1^{-/-}$mice $(P<0.05)$. The $\mathrm{C}_{\max }$ value of ET in Mrp2 $2^{-1-}$ mice was more than threefold higher than that in wild-type FVB mice $(P<0.05)$. The $\mathrm{AUC}_{0-\infty}$ ratios of ET-G to ET (Metabolite/Parent AUC ratios, M/P AUC ratios) in wild-type FVB mice, $\mathrm{Bcrp} 1^{-/-}$mice, and $\mathrm{Mrp} 2^{-/-}$mice were $103.61,41.50$, and 15.98, respectively. The pharmacokinetic profiles after i.v. injection (i.v.) of $2 \mathrm{mg} / \mathrm{kg}(11.23 \mu \mathrm{mol} / \mathrm{kg})$ ET are shown in Fig. 1, C and D, and the pharmacokinetic parameters are shown in Table 2. The $\mathrm{AUC}_{0-\infty}$ value of ET was significantly increased from $5.88 \pm 4.93$ minutes $\bullet \mu \mathrm{mol} / \mathrm{l}$ in 

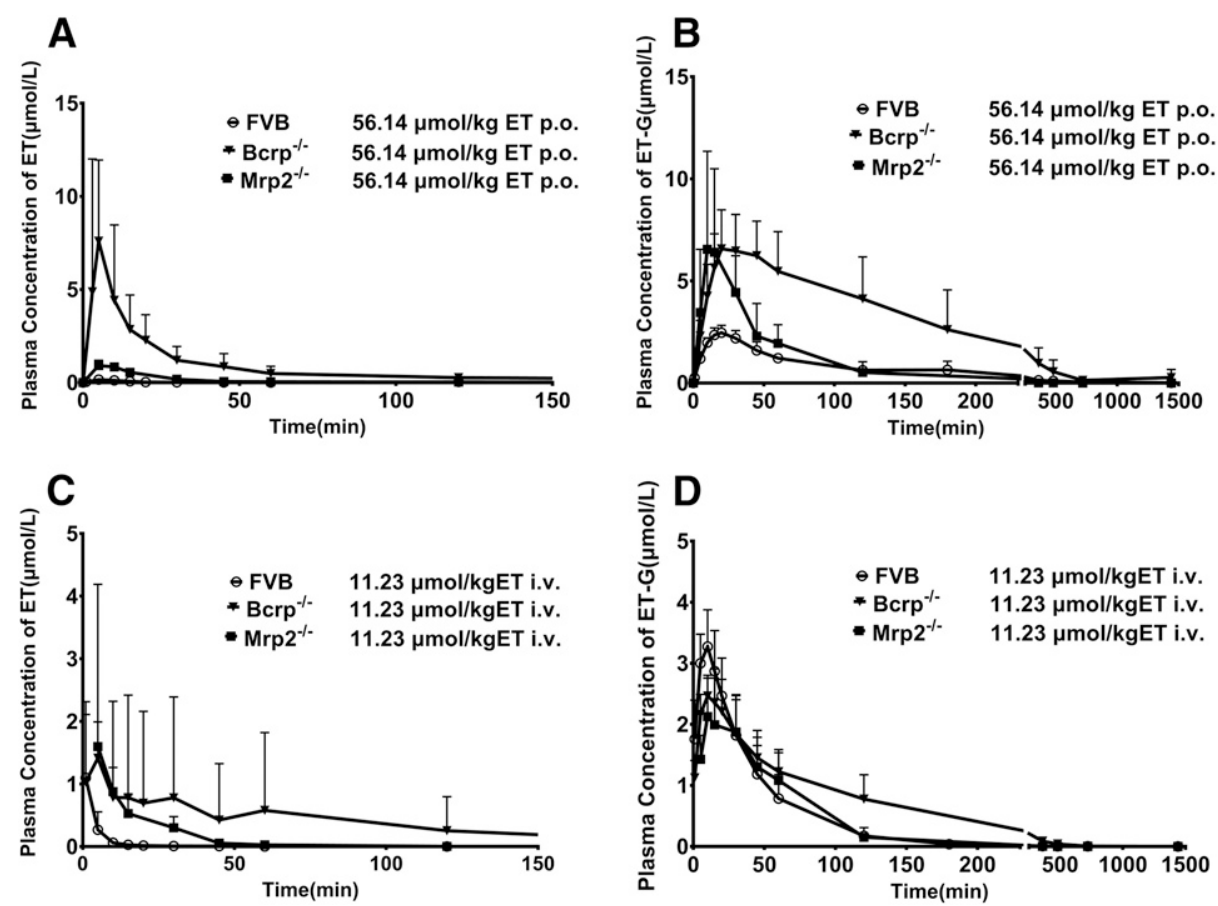

Fig. 1. Mean plasma concentration-time curves of ET (A and C) and ET-G (B and D) following oral $10 \mathrm{mg} / \mathrm{kg}(56.14 \mu \mathrm{mol} / \mathrm{kg})$ and i.v. $2 \mathrm{mg} / \mathrm{kg}$ $(11.23 \mu \mathrm{mol} / \mathrm{kg})$ administration of ET in wild-type, $\mathrm{Bcrp}^{-1-}$, and $\mathrm{Mrp}^{-/-} \mathrm{FVB}$ mice. Blood samples were collected from the tail vein of mice and were analyzed using UHPLC-MS/MS. The pharmacokinetic parameters of oral administration and i.v. injection are shown in Tables 1 and 2, respectively. The data points are presented as the average plasma concentrations of ET or ET-G, and the error bars represent the S.D. of the mean $(n=5)$.

wild-type FVB mice to $32.04 \pm 8.47$ minutes $\bullet \mu \mathrm{mol} / \mathrm{l}$ in $\mathrm{Mrp} 2^{-/-}$mice $(P<0.05)$. The $\mathrm{AUC}_{0-\infty}$ value of ET-G was also significantly increased from $155.76 \pm 50.41$ minutes $\bullet \mu \mathrm{mol} / \mathrm{l}$ in wild-type $\mathrm{FVB}$ mice to $259.85 \pm$ 69.20 minutes $\bullet \mu \mathrm{mol} / \mathrm{l}$ in $\mathrm{Bcrp}^{-/-}$mice $(P<0.05)$. The average absolute $\overline{F \%}$ of ET in wild-type FVB mice, $\mathrm{Bcrp}^{-/-}$mice, and $\mathrm{Mrp} 2^{-/-}$ mice were $10.07 \%, 17.10 \%$, and $14.66 \%$, respectively. Additionally, the $\mathrm{AUC}_{0-\infty}$ ratios of ET-G to ET (M/P AUC ratios) in wild-type FVB mice, $\mathrm{Bcrp}^{-/-}$mice, and $\mathrm{Mrp} 2^{-/-}$mice were $26.50,6.80$, and 4.52, respectively.

The mean plasma concentration-time curves after oral administration of $10 \mathrm{mg} / \mathrm{kg}(52.03 \mu \mathrm{mol} / \mathrm{kg}) 4-\mathrm{ME}$ in wild-type, Bcrp1 ${ }^{-/-}$, and Mrp2 ${ }^{-1-}$ FVB mice are shown in Fig. 2, A and B, and the pharmacokinetic parameters are shown in Table 3 . The $\mathrm{AUC}_{0-\infty}$ value of $4-\mathrm{ME}$ in $\mathrm{Bcrp}^{-/-}$mice $(193.56 \pm 42.58$ minutes $\bullet \mu \mathrm{mol} / \mathrm{l})$ was significantly higher than that in wild-type FVB mice $(64.23 \pm$ 18.52 minutes $\bullet \mu \mathrm{mol} / \mathrm{l})(P<0.05)$. The $\mathrm{AUC}_{0-\infty}$ values of $4-\mathrm{ME}-\mathrm{G}$ in $\mathrm{Bcrp} 1^{-/-}$mice $(733.70 \pm 202.51$ minutes $\bullet \mu \mathrm{mol} / \mathrm{l})$ and $\mathrm{Mrp} 2^{-/-}$ mice $(535.13 \pm 81.20$ minutes $\bullet \mu \mathrm{mol} / \mathrm{l})$ were also significantly higher than that in wild-type FVB mice $(375.21 \pm 114.50$ minutes $\bullet \mu \mathrm{mol} / \mathrm{l})$
$(P<0.05)$. The $\mathrm{AUC}_{0-\infty}$ ratios of $4-\mathrm{ME}-\mathrm{G}$ to $4-\mathrm{ME}$ (M/P AUC ratios) in wild-type FVB mice, Bcrp $1^{-/-}$mice, and $\mathrm{Mrp} 2^{-/-}$mice were 5.84, 3.79 , and 5.18, respectively. The pharmacokinetic profiles after the i.v. injection (i.v.) of $2 \mathrm{mg} / \mathrm{kg}(10.41 \mu \mathrm{mol} / \mathrm{kg}) 4-\mathrm{ME}$ are shown in Fig. 2, C and $\mathrm{D}$, and the pharmacokinetic parameters are shown in Table 4 . The $\mathrm{AUC}_{0-\infty}$ values of $4-\mathrm{ME}-\mathrm{G}$ in $\mathrm{Bcrp}^{-/-}(162.83 \pm 33.01$ minutes $\bullet \mu \mathrm{mol} / \mathrm{l})$ and $\mathrm{Mrp} 2^{-/-}$mice $(175.29 \pm 33.66$ minutes $\bullet \mu \mathrm{mol} / \mathrm{l})$ were significantly higher than that in wild-type FVB mice $(55.08 \pm 13.80$ minutes $\bullet \mu \mathrm{mol} / \mathrm{l})$ $(P<0.05)$. The $\overline{F \%}$ of $4-\mathrm{ME}$ in wild-type FVB mice, $\mathrm{Bcrp}^{-/-}$mice, and $\mathrm{Mrp}^{-1-}$ mice were $22.28 \%, 45.70 \%$, and $22.97 \%$, respectively. The $\mathrm{AUC}_{0-\infty}$ ratios of 4-ME-G to 4-ME (M/P AUC ratios) in wild-type FVB mice, $\mathrm{Bcrp} 1^{-/-}$mice, and $\mathrm{Mrp} 2^{-/-}$mice were $0.96,1.92$, and 1.95, respectively.

Absorption and Metabolic Characteristics of ET and 4-ME in Caco-2 Monolayers. Figure 3 shows the absorption and metabolic characteristics of ET and 4-ME in Caco- 2 cells. The mean $P_{a p p}$ values of ET were significantly higher than those of 4-ME regardless of whether the transportation direction was from the AP side to basolateal side (AP-BL) or from the BL side to AP side (BL-AP) (Fig. 3A) $(P<0.05)$.

TABLE 1

Pharmacokinetic parameters of ET and ET-G in wild-type, Bcrp1 ${ }^{-/-}$, and $\mathrm{Mrp2}^{-1-}$ FVB mice after oral administration of $10 \mathrm{mg} / \mathrm{kg}(56.14 \mu \mathrm{mol} / \mathrm{kg}) \mathrm{ET}$ Data are presented as means \pm S.D. $(\mathrm{n}=5)$; unpaired Student's $t$ test was used to analyze the data.

\begin{tabular}{|c|c|c|c|c|c|c|}
\hline \multirow{2}{*}{ Parameters } & \multicolumn{3}{|c|}{ ET } & \multicolumn{3}{|c|}{ ET-G } \\
\hline & FVB & Bcrp $1^{-1-}$ & $\operatorname{Mrp} 2^{-1-}$ & FVB & $\mathrm{Bcrp} 1^{-1-}$ & $\operatorname{Mrp} 2^{-1-}$ \\
\hline $\mathrm{C}_{\max }(\mu \mathrm{mol} / \mathrm{l})$ & $0.20 \pm 0.11$ & $0.64 \pm 0.43 *$ & $0.93 \pm 0.26^{*}$ & $2.46 \pm 0.36$ & $7.58 \pm 1.65^{*}$ & $7.79 \pm 4.33$ \\
\hline $\mathrm{T}_{\max }(\min )$ & $5.83 \pm 2.24$ & $5.00 \pm 0.00$ & $7.00 \pm 2.74$ & $22.00 \pm 4.72$ & $38.33 \pm 19.66$ & $19.00 \pm 10.25$ \\
\hline $\operatorname{AUC}_{0-\mathrm{t}}(\min \bullet \mu \mathrm{mol} / \mathrm{l})$ & $2.85 \pm 0.94$ & $16.98 \pm 6.10^{*}$ & $22.72 \pm 8.69^{*}$ & $297.50 \pm 105.05$ & $1325.21 \pm 658.29 *$ & $374.56 \pm 114.17$ \\
\hline $\mathrm{AUC}_{0-\infty}(\mathrm{min} \bullet \mu \mathrm{mol} / \mathrm{l})$ & $2.96 \pm 0.98$ & $32.68 \pm 14.49 *$ & $23.48 \pm 9.96^{*}$ & $306.68 \pm 113.93$ & $1356.30 \pm 666.51 *$ & $375.14 \pm 133.99$ \\
\hline $\mathrm{T}_{1 / 2}(\min )$ & $32.54 \pm 21.32$ & $278.39 \pm 201.85^{*}$ & $50.11 \pm 25.81$ & $161.28 \pm 112.79$ & $188.82 \pm 46.56$ & $57.26 \pm 36.81 *$ \\
\hline MRT (min) & $33.20 \pm 25.88$ & $330.15 \pm 254.85^{*}$ & $31.16 \pm 11.71$ & $157.21 \pm 69.54$ & $188.54 \pm 60.90$ & $48.18 \pm 14.87 *$ \\
\hline $\mathrm{V}_{\mathrm{d}}(1 / \mathrm{kg})$ & $125.77 \pm 67.89$ & $114.56 \pm 32.14$ & $91.63 \pm 34.06$ & N/A & - & - \\
\hline $\mathrm{CL} / \mathrm{F}(1 /$ min per kilogram) & $0.43 \pm 0.22$ & $0.28 \pm 0.05 *$ & $1.2 \pm 0.67^{*}$ & - & - & - \\
\hline $\mathrm{M} / \mathrm{P}$ AUC ratios & 103.61 & 41.50 & 15.98 & - & - & - \\
\hline
\end{tabular}

$\mathrm{M} / \mathrm{P}$ AUC ratios, the $\mathrm{AUC}_{0-\infty}$ ratio of ET-G to ET; $\mathrm{T}_{1 / 2}$, half-life; $\mathrm{T}_{\max }$, time to reach maximum plasma concentration.

$* P<0.05$ indicates a statistically significant difference between wild-type FVB mice and Bcrp $1^{-/-}$mice (or Mrp2 $2^{-/-}$mice). 
TABLE 2

Pharmacokinetic parameters of ET and ET-G in wild-type, Bcrp1 ${ }^{-/-}$, and Mrp2 $2^{-/-}$FVB mice after i.v. injection of $2 \mathrm{mg} / \mathrm{kg}(11.23 \mu \mathrm{mol} / \mathrm{kg}) \mathrm{ET}$

Data are presented as means \pm S.D. $(\mathrm{n}=5)$; unpaired Student's t test was used to analyze the data.

\begin{tabular}{|c|c|c|c|c|c|c|}
\hline \multirow{2}{*}{ Parameters } & \multicolumn{3}{|c|}{ ET } & \multicolumn{3}{|c|}{ ET-G } \\
\hline & FVB & $\mathrm{Bcrp}^{-1-}$ & $\operatorname{Mrp} 2^{-1-}$ & FVB & $\mathrm{Bcrp} 1^{-1-}$ & $\mathrm{Mrp} 2^{-/-}$ \\
\hline $\mathrm{AUC}_{0-\mathrm{t}}(\mathrm{min} \bullet \mu \mathrm{mol} / \mathrm{l})$ & $5.85 \pm 4.92$ & $26.92 \pm 55.50$ & $31.67 \pm 8.05^{*}$ & $155.04 \pm 50.73$ & $257.39 \pm 68.71^{*}$ & $143.87 \pm 41.24$ \\
\hline $\operatorname{AUC}_{0-\infty}(\min \bullet \mu \mathrm{mol} / \mathrm{l})$ & $5.88 \pm 4.93$ & $38.22 \pm 80.67$ & $32.04 \pm 8.47 *$ & $155.76 \pm 50.41$ & $259.85 \pm 69.20^{*}$ & $144.79 \pm 40.94$ \\
\hline $\mathrm{T}_{1 / 2}(\mathrm{~min})$ & $25.57 \pm 15.33$ & $22.50 \pm 26.56$ & $8.05 \pm 1.69$ & $32.87 \pm 8.07$ & $74.57 \pm 25.02 *$ & $28.25 \pm 5.61$ \\
\hline MRT (min) & $14.21 \pm 16.20$ & $15.21 \pm 17.60$ & $10.79 \pm 1.58$ & $39.28 \pm 10.87$ & $100.35 \pm 32.19^{*}$ & $42.73 \pm 6.63$ \\
\hline $\mathrm{V}_{\mathrm{d}}(1 / \mathrm{kg})$ & $33.79 \pm 36.44$ & $65.04 \pm 41.11$ & $4.2 \pm 0.86$ & - & - & - \\
\hline CL (1/min per kilogram) & $4.33 \pm 3.89$ & $9.58 \pm 6.99$ & $0.37 \pm 0.09$ & - & - & - \\
\hline $\mathrm{M} / \mathrm{P}$ AUC ratios & 26.50 & 6.80 & 4.52 & N/A & - & - \\
\hline$\overline{F \%}$ & 10.07 & 17.10 & 14.66 & & & \\
\hline
\end{tabular}

$\mathrm{M} / \mathrm{P}$ AUC ratios, the $\mathrm{AUC}_{0-\infty}$ ratio of ET-G to ET; $\mathrm{T}_{1 / 2}$, half-life.

$* P<0.05$ indicates a statistically significant difference between wild-type $\mathrm{FVB}$ mice and $\mathrm{Bcrp1}^{-/-}$mice (or Mrp2 ${ }^{-/-}$mice).

The mean $P_{a p p}$ values of ET and 4-ME in AP-BL were $2.36 \times 10^{-5}$ and $0.59 \times 10^{-5} \mathrm{~cm} / \mathrm{s}$, respectively. The mean $P_{a p p}$ values of ET and 4-ME in BL-AP were $2.55 \times 10^{-5}$ and $0.69 \times 10^{-5} \mathrm{~cm} / \mathrm{s}$, respectively (Fig. $3 \mathrm{~A})$. In the transport experiment, 4-ME showed significantly larger metabolized fractions $\left(F_{m e t}\right)$ than those of ET in AP-BL $(0.11$ for ET vs. 0.25 for $4-\mathrm{ME}$ ) and BL-AP (0.10 for ET vs. 0.27 for 4-ME) (Fig. 3B) $(P<0.05)$, and 4-ME yielded lower intracellular concentrations than ET in both AP-BL (0.039 mM for ET vs. $0.0048 \mathrm{mM}$ for 4-ME) and BL-AP (0.042 mM for ET vs. $0.007 \mathrm{mM}$ for 4-ME) (Fig. 3C). For the ET and 4-ME glucuronides in the transport experiment, 4-ME-G also produced lower intracellular concentrations than ET-G in both AP-BL $(0.016 \mathrm{mM}$ for ET-G vs. $0.0068 \mathrm{mM}$ for 4-ME-G) and BL-AP (0.022 mM for ET-G vs. $0.0055 \mathrm{mM}$ for 4-ME-G) (Fig. 3D) $(P<0.05)$. For the AP-BL transport experiment, the $J$ of 4-ME-G were 2.65 - and 1.58 -fold higher than those of ET-G on the BL and AP sides, respectively (Fig. 3E) $(P<0.05)$. For the BL-AP transport experiment, the $J$ of 4-ME-G were 2.58- and 1.82-fold higher than those of ET-G on the AP and BL sides, respectively (Fig. 3F) $(P<0.05)$. For the AP-BL transport experiment, the $C L$ rates of $4-\mathrm{ME}-\mathrm{G}$ were 6.64- and 3.98-fold higher than those of ET-G on the AP and BL sides, respectively (Fig. 3G) $(P<0.05)$. For the BL-AP transport experiment, the $C L$ rates of 4-ME-G were 11.12- and 8.16-fold higher than those of ET-G on the AP and BL sides, respectively (Fig. $3 \mathrm{H})(P<0.05)$.

Effects of Inhibitors on the Glucuronidation Disposition of ET and 4-ME in Caco-2 Monolayers. The effects of Ko143 (BCRP inhibitor) and MK571(MRPs inhibitor) on the glucuronidation disposition of ET and 4-ME are presented in Fig. 4. The excretion amounts of ET-G and 4-ME-G on the BL sides were 5- to 8-fold more, respectively, than those of ET-G and 4-ME-G on the AP side regardless of the side where the substrates were loaded. The excretion amounts of ET-G on both the AP and BL sides were significantly decreased in the presence of $5 \mu \mathrm{M}$ Ko143 and $10 \mu \mathrm{M}$ MK571 (Fig. 4, A-D). Similar results were observed in the excretion of 4-ME-G in the presence of $5 \mu \mathrm{M}$ Ko143 and $10 \mu$ M MK571 (Fig. 4, E-H). The effects of Ko143 and MK571 on the $J$ and $C L$ of glucuronides (ET-G and 4-ME-G) are shown in Fig. 5. Ko143 and MK571 significantly reduced the $J$ and $C L$ values of ET-G in the bidirectional transport experiment (Fig. 5, A, B, E, and F) $(P<0.05)$. Unlike that of ET-G, Ko143 reduced the $J$ of 4-ME-G on both the AP and BL sides when 4-ME was loaded on the AP side (Fig. 5C) $(P<0.05)$, but
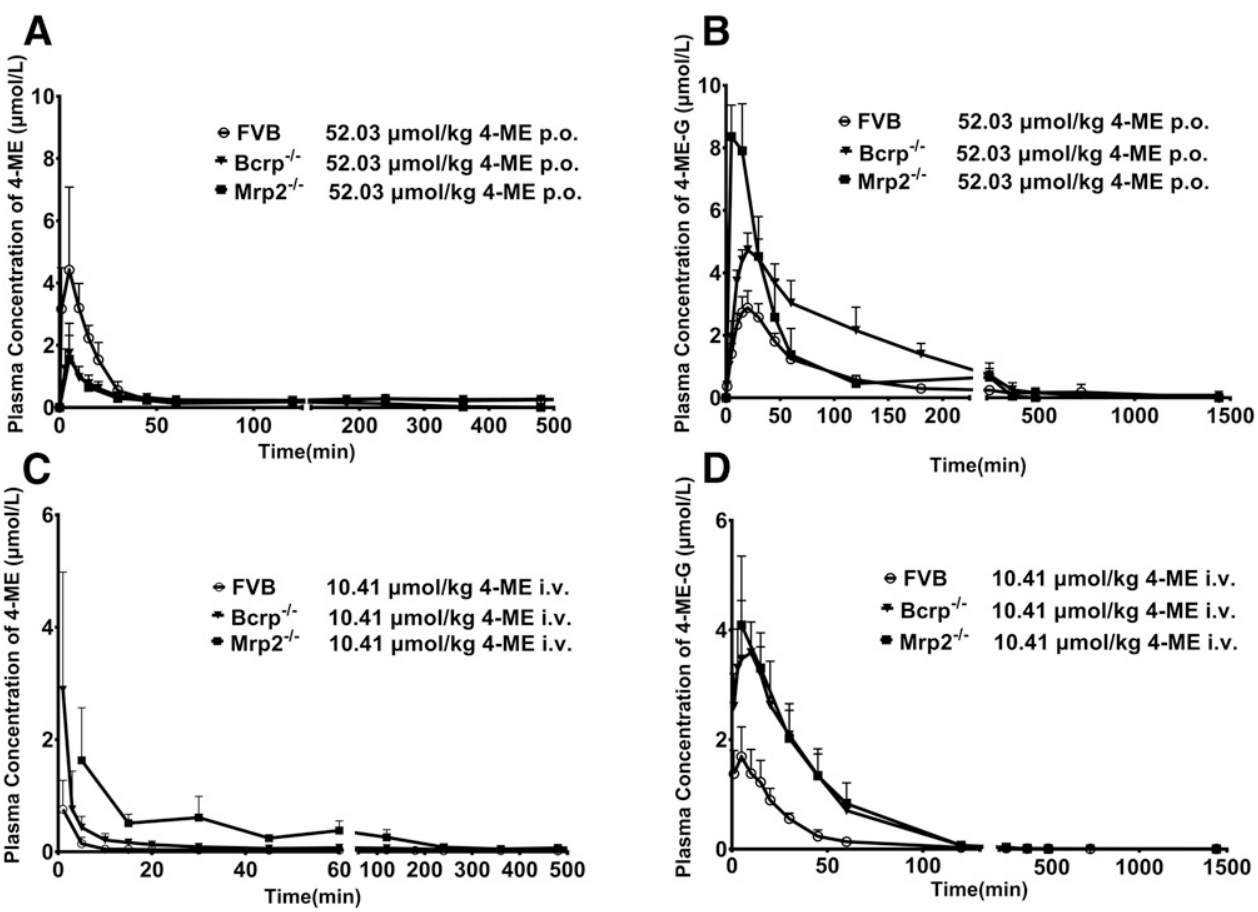

Fig. 2. Mean plasma concentration-time curves of 4-ME (A and C) and 4-ME-G (B and D) following oral $10 \mathrm{mg} / \mathrm{kg}(52.03 \mu \mathrm{mol} / \mathrm{kg})$ and i.v. $2 \mathrm{mg} / \mathrm{kg}(10.41 \mu \mathrm{mol} / \mathrm{kg})$ administration of 4-ME in wild-type, $\mathrm{Bcrp}^{-1-}$, and $\mathrm{Mrp}^{-1-}$ FVB mice. Blood samples were collected from the tail vein of mice and were analyzed using UHPLC-MS/MS. The pharmacokinetic parameters of oral administration and i.v. injection are shown in Tables 3 and 4, respectively. The data points are presented as the average plasma concentrations of 4-ME or 4-ME-G, and the error bars represent the S.D. of the mean $(n=5)$. 
TABLE 3

Pharmacokinetic parameters of 4-ME and 4-ME-G in wild-type, Bcrp1 ${ }^{-1-}$, and Mrp2 ${ }^{-1-}$ FVB mice after oral administration of $10 \mathrm{mg} / \mathrm{kg}(52.03 \mu \mathrm{mol} / \mathrm{kg}) 4-\mathrm{ME}$

Data are presented as means \pm S.D. $(\mathrm{n}=5)$; unpaired Student's test was used to analyze the data.

\begin{tabular}{|c|c|c|c|c|c|c|}
\hline \multirow{2}{*}{ Parameters } & \multicolumn{3}{|c|}{ 4-ME } & \multicolumn{3}{|c|}{ 4-ME-G } \\
\hline & FVB & Bcrp $1^{-/-}$ & $\mathrm{Mrp2}^{-1-}$ & FVB & $\mathrm{Bcrp}^{-1-}$ & $\mathrm{Mrp}^{-1-}$ \\
\hline $\mathrm{C}_{\max }(\mu \mathrm{mol} / \mathrm{l})$ & $2.50 \pm 1.17$ & $1.42 \pm 0.48$ & $1.55 \pm 0.77$ & $2.90 \pm 0.52$ & $4.59 \pm 0.32$ & $8.97 \pm 0.87 *$ \\
\hline $\mathrm{T}_{\max }(\min )$ & $6.00 \pm 2.24$ & $6.00 \pm 2.24$ & $5.00 \pm 0.00$ & $19.17 \pm 2.04$ & $19.00 \pm 2.24$ & $15.00 \pm 0.00$ \\
\hline $\mathrm{AUC}_{0-\mathrm{t}}(\mathrm{min} \bullet \mu \mathrm{mol} / \mathrm{l})$ & $61.93 \pm 18.88$ & $108.07 \pm 11.96^{*}$ & $87.12 \pm 26.98$ & $371.21 \pm 113.84$ & $681.43 \pm 157.16^{*}$ & $532.70 \pm 80.79 *$ \\
\hline $\operatorname{AUC}_{0-\infty}(\min \bullet \mu \mathrm{mol} / \mathrm{l})$ & $64.23 \pm 18.52$ & $193.56 \pm 42.58^{*}$ & $103.34 \pm 20.35$ & $375.21 \pm 114.50$ & $733.70 \pm 202.51^{*}$ & $535.13 \pm 81.20^{*}$ \\
\hline $\mathrm{T}_{1 / 2}(\min )$ & $130.00 \pm 55.09$ & $241.76 \pm 106.34 *$ & $122.22 \pm 35.74$ & $195.68 \pm 43.72$ & $465.19 \pm 299.84$ & $57.82 \pm 5.16^{*}$ \\
\hline MRT (min) & $49.58 \pm 20.92$ & $154.41 \pm 13.71^{*}$ & $141.59 \pm 55.18^{*}$ & $258.15 \pm 119.28$ & $206.01 \pm 62.37$ & $86.15 \pm 9.88^{*}$ \\
\hline$V_{d}(1 / k g)$ & $125.77 \pm 67.89$ & $114.56 \pm 32.14$ & $91.63 \pm 34.06$ & & & \\
\hline CL/F (1/min per kilogram) & $0.43 \pm 0.22$ & $0.28 \pm 0.05$ & $1.2 \pm 0.67^{*}$ & N/A & - & - \\
\hline M/P AUC ratios & 5.84 & 3.79 & 5.18 & - & - & - \\
\hline
\end{tabular}

$\mathrm{M} / \mathrm{P}$ AUC ratios, the $\mathrm{AUC}_{0-\infty}$ ratio of 4-ME-G to 4-ME; $\mathrm{T}_{1 / 2}$, half-life; $\mathrm{T}_{\max }$, time to reach maximum plasma concentration.

$* P<0.05$ indicates a statistically significant difference between wild-type FVB mice and $\mathrm{Bcrp1}^{-1-}$ mice (or Mrp2 $2^{-l-}$ mice).

their $J$ and $C L$ values were not significantly inhibited by MK571 (Fig. 5, D, G, and H). The intracellular concentrations of ET-G were significantly decreased by Ko143 in the BL-AP transport experiment $(P<0.05)$, whereas the intracellular concentrations of 4-ME-G were not changed on both sides (Fig. 6, A and B). MK571 did not alter the intracellular concentrations of ET-G and 4-ME-G regardless of the side on which the ET (or 4-ME) was loaded. MK571 significantly decreased the $F_{m e t}$ of ET-G (Fig. 6C). Ko143 and MK571 did not influence the $F_{m e t}$ of $4-\mathrm{ME}-\mathrm{G}$ in the transport experiment (Fig. 6D).

Glucuronidation Disposition of ET and 4-ME in Wild-Type, Bcrp1 $^{-1-}$, and Mrp2 $2^{-1-}$ FVB Mice. The perfused mouse model was used to further confirm the role of Bcrp1 and Mrp2 in the disposition of ET (Fig. 7) and 4-ME (Fig. 8). The $P^{*}$ eff of ET (or 4-ME) and amount of ET (or 4-ME) absorbed and percentage of excreted ET-G (or 4-ME-G) in a 15-minute interval were determined and normalized over a $10-\mathrm{cm}$ intestinal length. The exposure levels of ET-G (or 4-ME-G) in bile and plasma at the end of the perfusion were determined by the ratio value $\left(\mathrm{A}_{\mathrm{ET}-\mathrm{G}} / \mathrm{A}_{\mathrm{IS}}\right)$ of the peak area of ET-G to the peak area of IS (testosterone) (or $\mathrm{A}_{4-\mathrm{ME}-\mathrm{G}} / \mathrm{A}_{\mathrm{IS}}$ ).

The $P^{*}$ eff values of ET in the upper small intestine (duodenum) ranged from $1.84 \pm 0.44$ to $2.18 \pm 0.37$ without a significant difference among the three mouse genotypes (Fig. 7A). The $P^{*}$ eff values of ET in colon are lower than those in duodenum and ranged from $0.58 \pm 0.59$ to $1.10 \pm$ 0.23 and without significant difference among the three mouse genotypes (Fig. 7A). The absorption features are also reflected by the absorbed amount of ET. The amount of ET absorbed ranged from $41.47 \pm 9.99$ to $50.05 \pm 5.44 \mathrm{nmol} / 15$ minutes without a significant difference among the three mouse genotypes (Fig. 7B). Compared with the duodenum, the amount of ET absorbed was lower and the values ranged from $13.00 \pm 13.31$ to $18.43 \pm 5.57 \mathrm{nmol} / 15$ minutes and without a significant difference among the three mouse genotypes (Fig. 7B). The percentage of ET-G excreted in the duodenum was significantly decreased from $34.71 \% \pm 9.84 \%$ in wild-type FVB mice to $7.52 \% \pm 1.91 \%$ in $\mathrm{Bcrp} 1^{-1-}$ mice (Fig. $\left.7 \mathrm{C}\right)(P<0.05)$, whereas that in $\mathrm{Mrp}^{-1-}$ mice is $37.27 \% \pm 9.91 \%$. Meanwhile, the peak area ratio of ET-G was significantly increased from $2.17 \pm 0.99$ in wildtype FVB mice to $9.64 \pm 1.75$ in Bcrp $1^{-/-}$mice (Fig. 7E) $(P<0.05)$, whereas the ratio value of ET-G $\left(\mathrm{A}_{\mathrm{ET}-\mathrm{G}} / \mathrm{A}_{\mathrm{IS}}\right)$ in $\mathrm{Mrp} 2^{-1-}$ mice was $2.68 \pm 0.25$. The exposure of ET-G in bile showed no significant alteration in both duodenum and colon among the three mouse genotypes. However, the ratio of ET-G $\left(\mathrm{A}_{\mathrm{ET}-\mathrm{G}} / \mathrm{A}_{\mathrm{IS}}\right)$ in the bile had decreased from $5.99 \pm 6.55$ in wild-type FVB mice to $1.58 \pm 0.75$ and $1.42 \pm 0.88$ in $\mathrm{Bcrp} 1^{-/-}$and $\mathrm{Mrp} 2^{-/-}$mice, respectively (Fig. 7D).

The $P^{*}$ eff values of 4-ME in the upper small intestine (duodenum) ranged from $1.81 \pm 0.39$ to $2.54 \pm 0.52$ (Fig. 7A). A slight but significant increase was noted in the $P^{*}$ eff value in $\mathrm{Bcrp}^{-1-}$ mice compared with that in wild-type FVB mice (Fig. 8A) $(P<0.05)$. The duodenum and colon showed comparative $P^{*}$ eff values and absorbed amounts for 4-ME (Fig. 8, A and B). The duodenum excreted more 4-ME-G than the colon in perfusate (Fig. 8C). The 4-ME-G showed higher concentrations in both bile and plasma than 4-ME (Fig. 8, D and E). The concentrations of $4-\mathrm{ME}-\mathrm{G}(13.67 \pm 10.10)$ were increased in the bile of Bcrp $1^{-1-}(7.48 \pm 5.34)$ and $\mathrm{Mrp}^{-1-}(2.25 \pm 1.72)$ mice compared with that in wild-type FVB mice, but the increase was not statistically significant.

TABLE 4

Pharmacokinetic parameters of 4-ME and 4-ME-G in wild-type, Bcrp1 ${ }^{-/-}$, and Mrp2 ${ }^{-1-}$ FVB mice after i.v. injection of 2 mg/kg (10.41 $\left.\mu \mathrm{mol} / \mathrm{kg}\right) 4-\mathrm{ME}$ Data are presented as means \pm S.D. $(\mathrm{n}=5)$; unpaired Student's $t$ test was used to analyze the data.

\begin{tabular}{|c|c|c|c|c|c|c|}
\hline \multirow{2}{*}{ Parameters } & \multicolumn{3}{|c|}{ 4-ME } & \multicolumn{3}{|c|}{ 4-ME-G } \\
\hline & FVB & $\mathrm{Bcrp}^{-/-}$ & $\operatorname{Mrp} 2^{-1-}$ & FVB & $\mathrm{Bcrp}^{-/-}$ & $\operatorname{Mrp} 2^{-1-}$ \\
\hline $\mathrm{AUC}_{0-\mathrm{t}}(\mathrm{min} \bullet \mu \mathrm{mol} / \mathrm{l})$ & $50.40 \pm 10.48$ & $75.22 \pm 14.08$ & $82.45 \pm 21.16$ & $53.66 \pm 13.56$ & $161.98 \pm 32.97 *$ & $174.35 \pm 34.12$ \\
\hline $\mathrm{AUC}_{0-\infty}(\min \bullet \mu \mathrm{mol} / \mathrm{l})$ & $57.66 \pm 11.13$ & $84.70 \pm 15.97$ & $89.99 \pm 25.31$ & $55.08 \pm 13.80$ & $162.83 \pm 33.01 *$ & $175.29 \pm 33.66^{*}$ \\
\hline $\mathrm{T}_{1 / 2}(\min )$ & $410.00 \pm 249.10$ & $329.55 \pm 153.40$ & $93.86 \pm 28.40$ & $96.00 \pm 51.36$ & $58.16 \pm 12.00$ & $30.27 \pm 7.64$ \\
\hline MRT (min) & $169.63 \pm 39.07$ & $160.18 \pm 27.25$ & $83.30 \pm 20.05$ & $45.81 \pm 4.72$ & $43.37 \pm 5.16$ & $33.58 \pm 6.89$ \\
\hline $\mathrm{V}_{\mathrm{d}}(\mathrm{l} / \mathrm{kg})$ & $61.44 \pm 21.08$ & $44.9 \pm 10.71$ & $19.48 \pm 8.07^{*}$ & N/A & - & - \\
\hline CL (1/min per kilogram) & $0.12 \pm 0.04$ & $0.09 \pm 0.03$ & $0.10 \pm 0.02$ & - & - & - \\
\hline $\mathrm{M} / \mathrm{P}$ AUC ratios & 0.96 & 1.92 & 1.95 & - & - & - \\
\hline$\overline{F \%}$ & 22.28 & 45.70 & 22.97 & & & \\
\hline
\end{tabular}

$\mathrm{M} / \mathrm{P}$ AUC ratios, the $\mathrm{AUC}_{0-\infty}$ ratio of 4-ME-G to 4-ME; $\mathrm{T}_{1 / 2}$, half-life

$* P<0.05$ indicates a statistically significant difference between wild-type FVB mice and Bcrp1 ${ }^{-1-}$ mice (or Mrp2 ${ }^{-/-}$mice). 
A

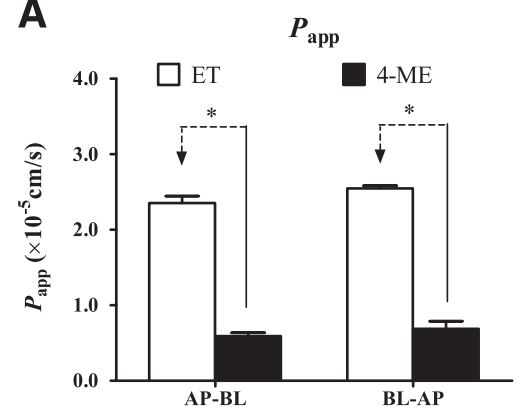

C

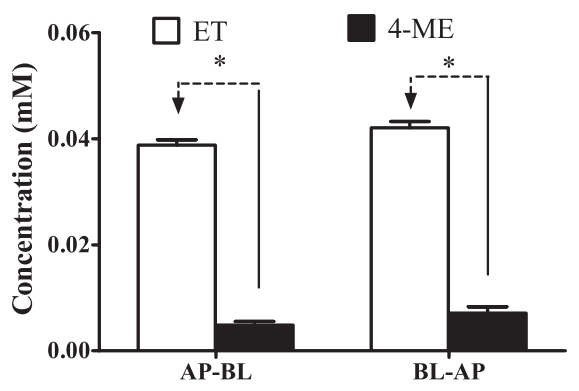

E

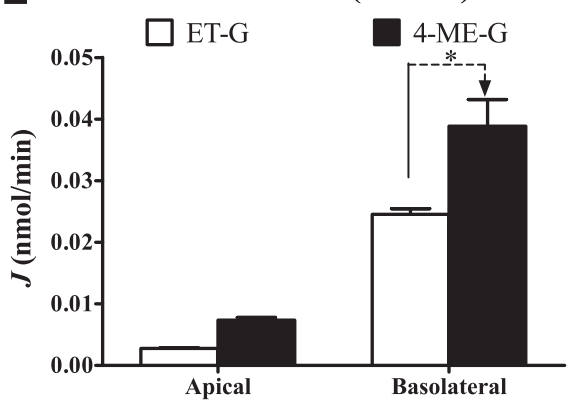

G

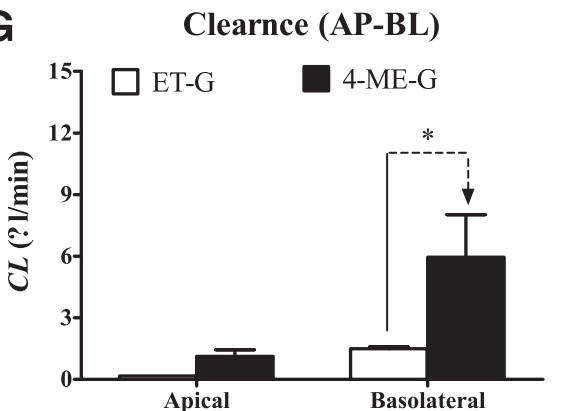

B

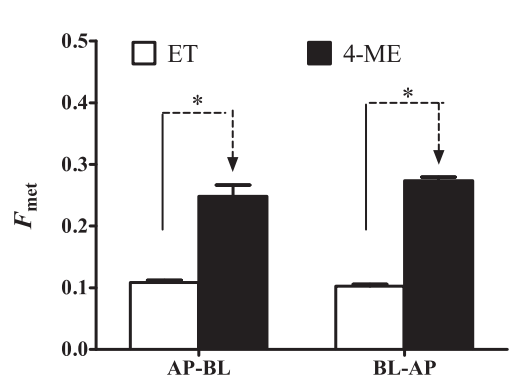

D Intracellular concentration
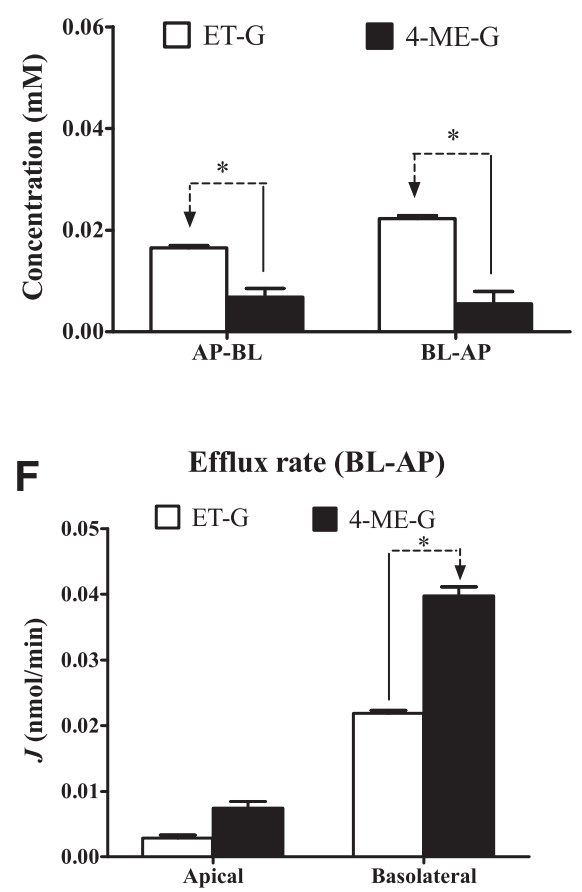

H

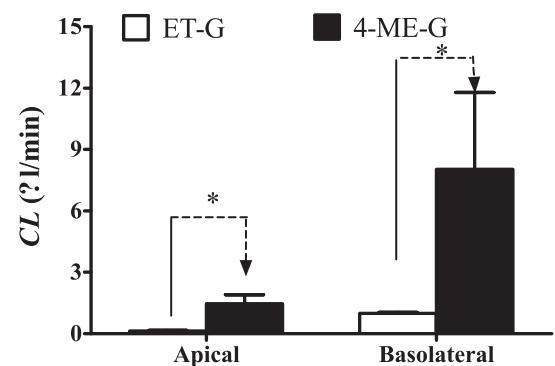

Fig. 3. Absorption and metabolic characteristics of ET and 4-ME in Caco-2 monolayers. ET or 4-ME $(10 \mu \mathrm{M})$ was loaded onto the AP side (AP-BL) or BL side (BL-AP) of Caco-2 monolayers. At $0.5,1,1.5$, and 2 hours, three samples $(500 \mu \mathrm{l})$ from both sides of each Transwell were collected and determined. (A) $P_{a p p}$ of ET and 4-ME; (B) metabolism fraction $\left(F_{m e t}\right)$ of ET and 4-ME; (C) intracellular ET and 4-ME concentrations; (D) intracellular ET-G and 4-ME-G concentrations; (E) $J$ of ET-G and 4-ME-G from the intracellular to the BL side (AP-BL); (F) $J$ of ET-G and 4-ME-G from the intracellular to the AP side (BL-AP); $(\mathrm{G}) C L$ of ET-G and 4-ME-G from the intracellular to the BL side (AP-BL); and (H) $C L$ of ET-G and 4-ME-G from the intracellular to the AP side (BL-AP). The data points represent the average values of the triplicate samples, and the error bars represent the S.D. of the mean. Unpaired Student's $t$ test was used to analyze the data. The asterisk $(*)$ indicates a statistically significant difference between ET and 4-ME (or ET-G and 4-ME-G) at $P<0.05$.

\section{Discussion}

In our previous study, we had demonstrated that both ET and 4-ME were metabolized to 7-O-glucuronides (ET-G and 4-ME-G, respectively) in human liver and intestinal microsomes (Zhu et al., 2015). The metabolism studies in rats and mice also showed that the 7-C position glucuronidation reaction is the unique metabolic pathway for ET and 4-ME (unpublished data). The transportation of glucuronides depends mostly on the excretion of transporters that are commonly located on the AP and BL membranes of many cells. Thus, in the current study, transporter knockout mice and Caco-2 cells were employed to explore the role of BCRP and MRP2 in the disposition of ET-G and 4-ME-G in vitro and in vivo.

The pharmacokinetic study and perfusion experiment in knockout mice and inhibition assays in Caco- 2 monolayers provided considerable evidence supporting the important role of BCRP and MRP2 in the excretion of ET-G and 4-ME-G. The pharmacokinetic data showed that 
A

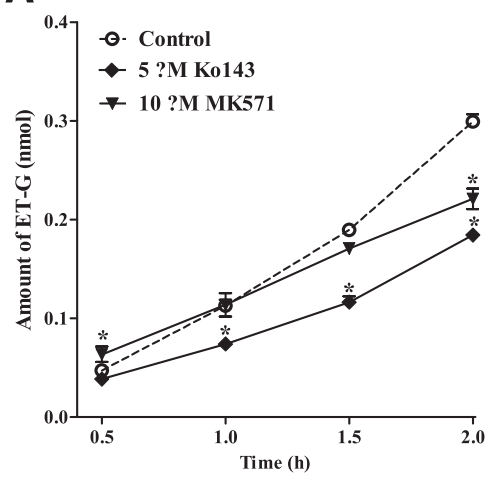

C

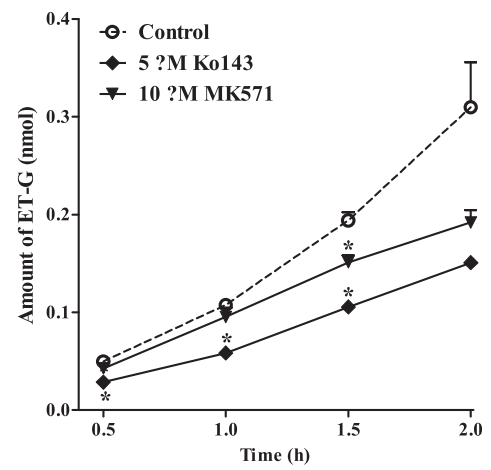

E

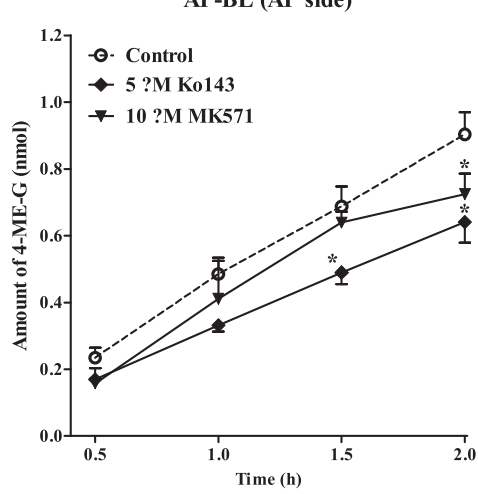

G

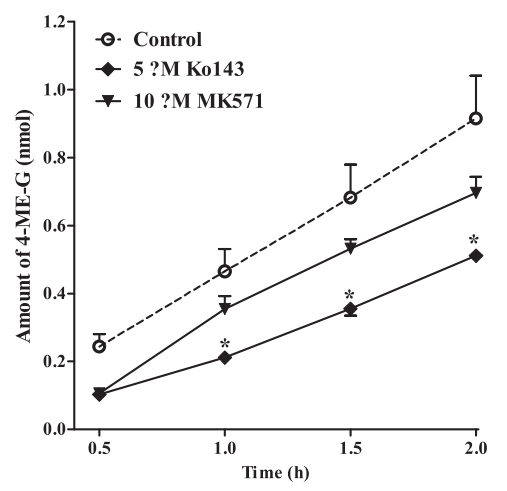

B

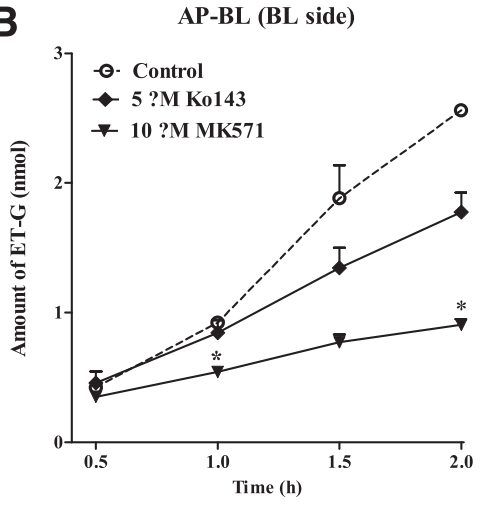

D

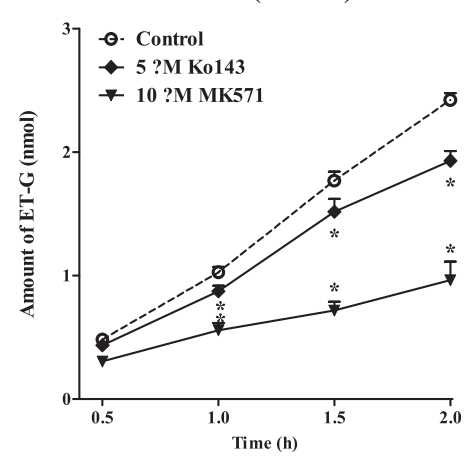

$\mathbf{F}$

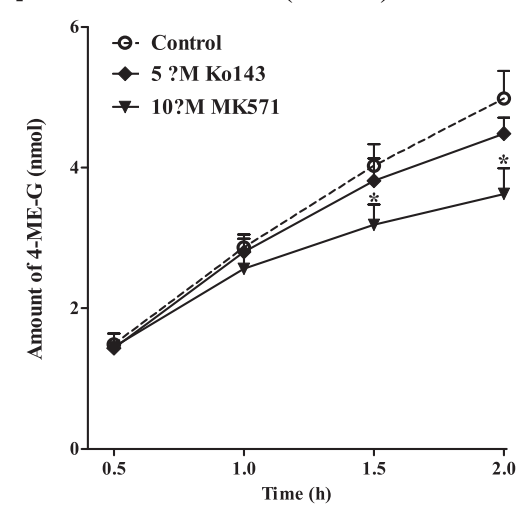

H

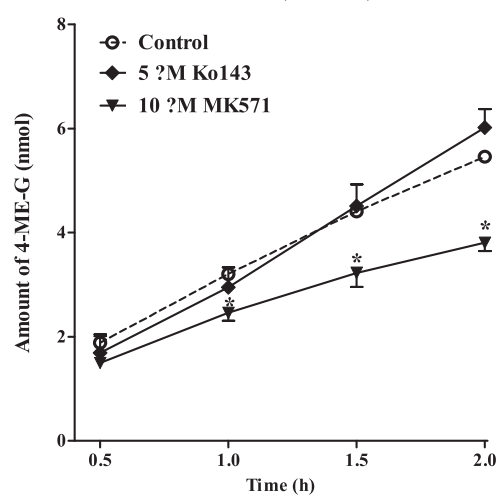

Fig. 4. Effects of Ko143 (inhibitor of BCRP) and MK571 (inhibitor of MRP2) on the excretion amounts of ET-G (A-D) and 4-ME-G $(\mathrm{E}-\mathrm{H})$ from the cellular membrane to the AP and BL sides. The experiment was set up as follows: ET or 4-ME $(10 \mu \mathrm{M})$ was loaded on the AP or BL side; Ko143 $(5 \mu \mathrm{M})$ or MK571 $(10 \mu \mathrm{M})$ was loaded on the AP side; or no inhibitor was added as the control group. The amounts of ET-G or 4-ME-G on the AP or BL side were determined at $0.5,1,1.5$, and 2 hours after incubation. The data points represent the average values of the triplicate samples, and the error bars represent the S.D. of the mean. Unpaired Student's $t$ test was used to analyze the data. The asterisk (*) indicates a statistically significant difference between the control and inhibited groups at $P<0.05$.
ET and 4-ME are mainly present as ET-G and 4-ME-G in plasma (Figs. 1 and 2). This result was consistent with our previous study showing that ET and 4-ME easily undergo 7-O glucuronidation metabolism by human hepatic and intestinal microsomes (Zhu et al., 2015). The pharmacokinetic parameters of ET-G and 4-ME-G in knockout mice exhibited significant differences from those in wild-type FVB mice (Tables 1-4). 
A Efflux rate of ET-G (AP-BL)

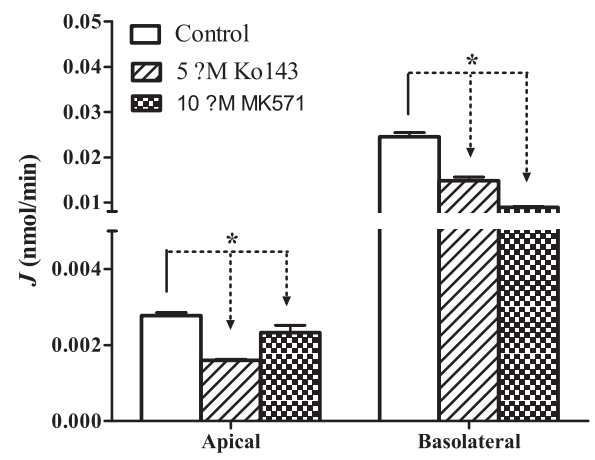

C

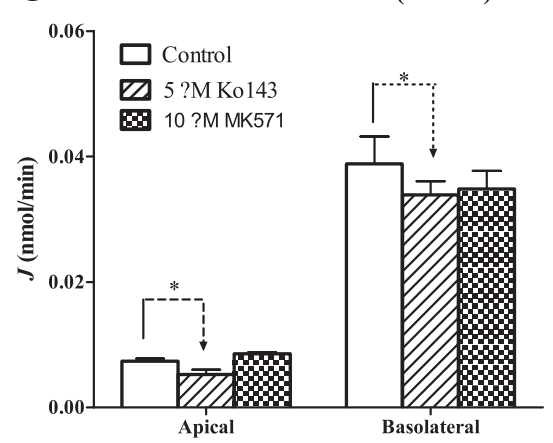

E

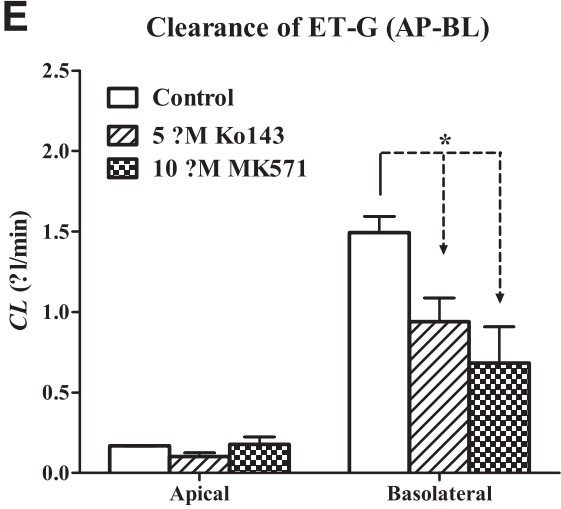

G

Clearance of 4-ME-G (AP-BL)

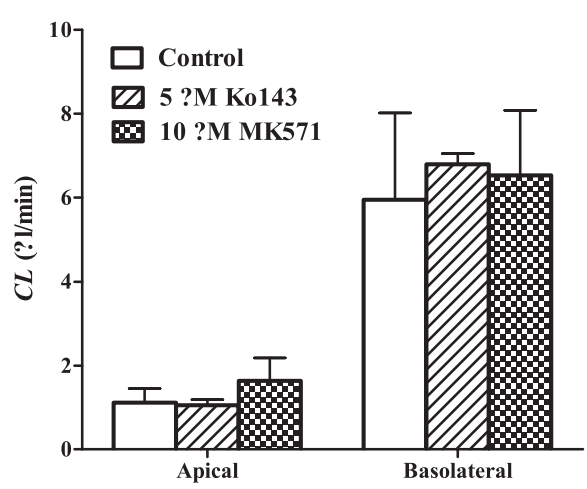

B Efflux rate of ET-G (BL-AP)

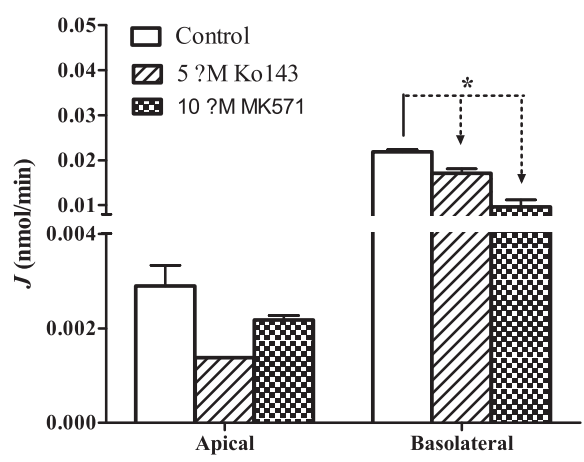

D Efflux rate of 4-ME-G (BL-AP)

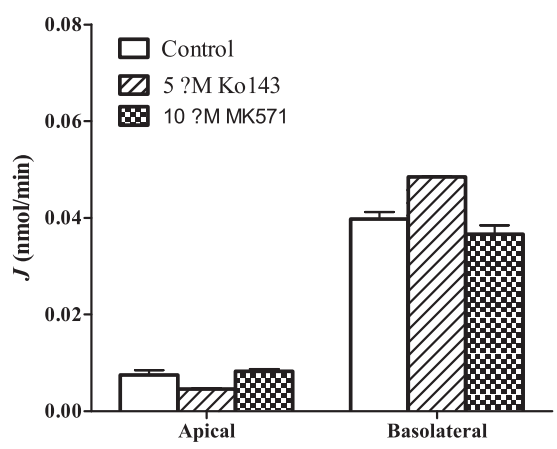

$\mathbf{F}$

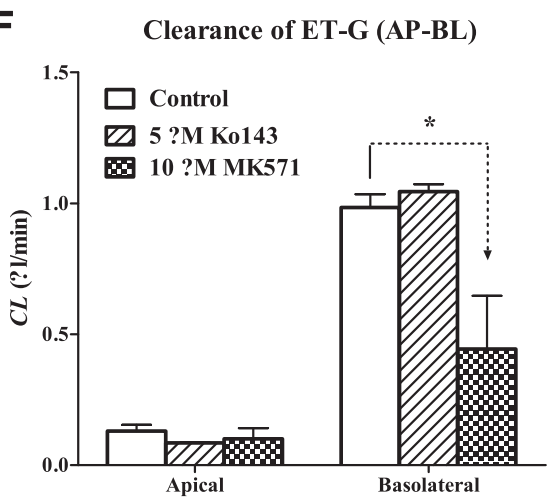

H

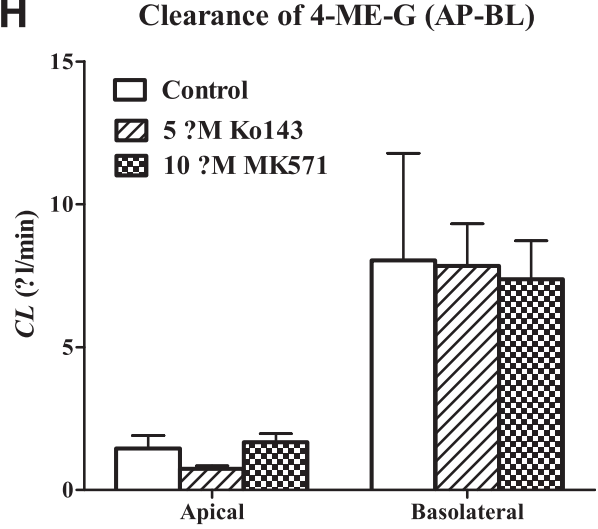

Fig. 5. Effect of Ko143 and MK571 on the $J$ of ET-G (A and B) and 4-ME-G (C and D) as well as the $C L$ rates of ET-G (E and F) and 4-ME-G (G and $\mathrm{H}$ ) at both the AP side to BL side (AP-BL) and $\mathrm{BL}$ side to AP side (BL-AP) directions in Caco-2 monolayers. The experiment was set up as follows: $10 \mu \mathrm{M}$ ET or 4-ME was loaded on the AP or BL side; Ko143 $(5 \mu \mathrm{M})$ or MK571 $(10 \mu \mathrm{M})$ was loaded on the AP side; or no inhibitor was added as the control group. The amounts of ET-G or 4-ME-G on the AP and BL sides as well as their intracellular concentrations were determined at 0.5 , $1,1.5$, and 2 hours after incubation. The data points represent the average values of the triplicate samples, and the error bars represent the S.D. of the mean. Unpaired Student's $t$ test was used to analyze the data. The asterisk $(*)$ indicates a statistically significant difference between the control and inhibited groups at $P<0.05$.
The $\mathrm{AUC}_{0-\infty}$ values of ET and 4-ME, and their glucuronides (ET-G and 4-ME-G), were significantly increased in most of $\mathrm{Bcrp}^{-/-}$and $\mathrm{Mrp}^{-I-}$ mice compared with those in wild-type FVB mice after oral or i.v. administration of ET or 4-ME. The average absolute $\overline{F \%}$ of ET and 4-ME were increased in $\mathrm{Bcrp}^{-1-}$ mice $(17.10 \%$ for ET and $45.70 \%$ for 4-ME) compared with those in wild-type FVB mice (10.07\% for ET 
A

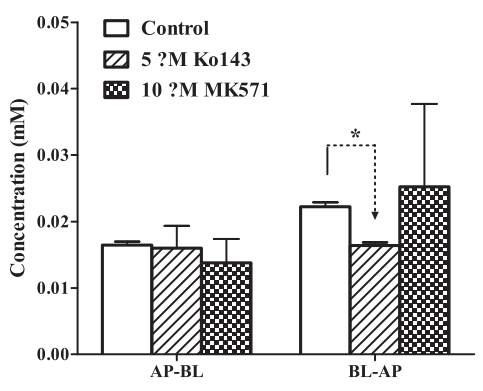

C

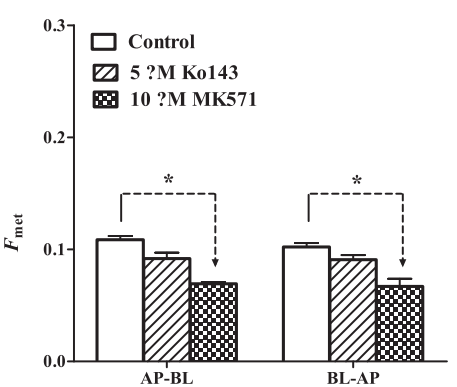

B

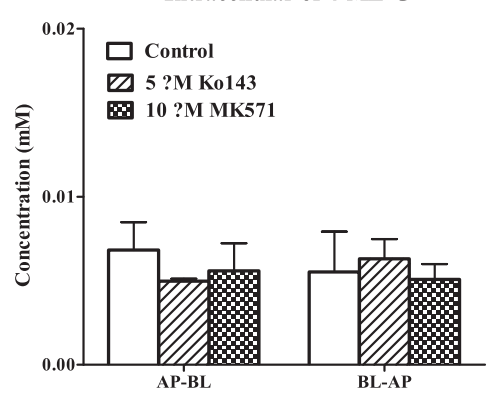

D

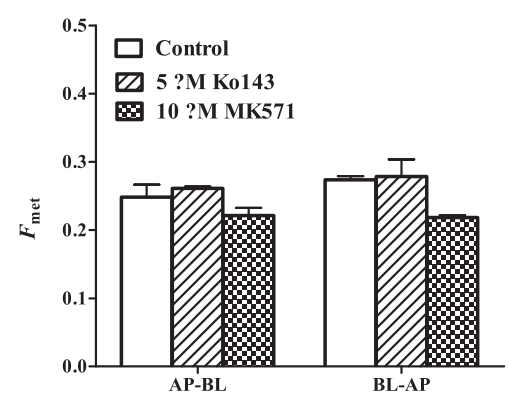

Fig. 6. Effect of Ko143 and MK57 on the intracellular concentrations of ET-G (A) and 4-ME-G (B), and metabolism fraction $\left(F_{m e t}\right)$ of ET (C) and 4-ME (D) on both the AP side to BL side (AP-BL) and $\mathrm{BL}$ side to $\mathrm{AP}$ side (BL-AP) in Caco-2 monolayers. The experiment was set up as follows: $10 \mu \mathrm{M}$ ET or 4-ME was loaded on the AP or BL side; Ko143 $(5 \mu \mathrm{M})$ or MK571 $(10 \mu \mathrm{M})$ was loaded on the AP side; or no inhibitor was added as the control group. The amounts of ET-G and 4-ME-G on the AP and BL sides as well as their intracellular concentrations were determined at 0.5 , $1,1.5$, and 2 hours after incubation. $F_{m e t}$ was determined by comparing the total amounts of glucuronides and the parent compound. The data points represent the average values of the triplicate samples, and the error bars represent the S.D. of the mean. Unpaired Student's $t$ test was used to analyze the data. The asterisk $\left(^{*}\right)$ indicates a statistically significant difference between the control and inhibited groups at $P<0.05$. and $22.28 \%$ for 4-ME) (Tables 2-4). These results suggested that Bcrp1 and Mrp2 might be involved in the disposition of ET-G and 4-ME-G. The inhibition assays in Caco-2 cells were conducted to verify the role of BCRP and MRP2 on the disposition of ET-G and 4-ME-G in vitro. In the inhibition assays in Caco-2 monolayers, the excretion of ET-G and 4-ME-G was significantly inhibited in the presence of the Ko143 (BCRP inhibitor) or MK571 (MRP2 inhibitor) on the AP side of Caco-2 monolayers (Fig. 4). The $J$ and $C L$ of ET-G and 4-ME-G were also significantly decreased by Ko143 and MK571 (Fig. 5). These results also suggested that BCRP and MRP2 are probably involved in excreting ET-G and 4-ME-G. Additionally, the perfusion experiment in transporter knockout mice showed that Bcrp1 deficiency significantly
A

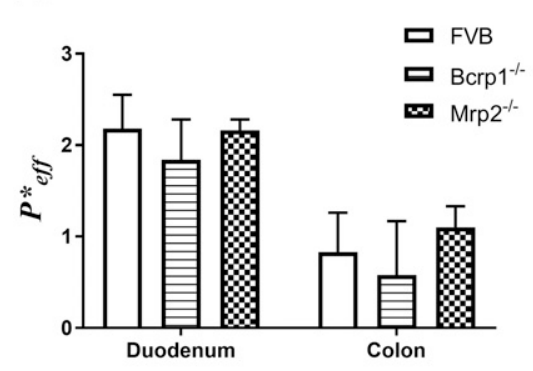

D
B

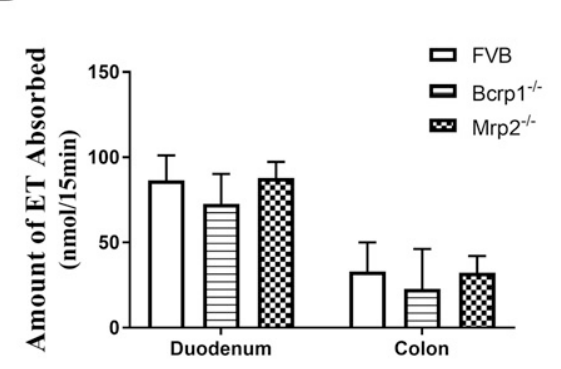

C

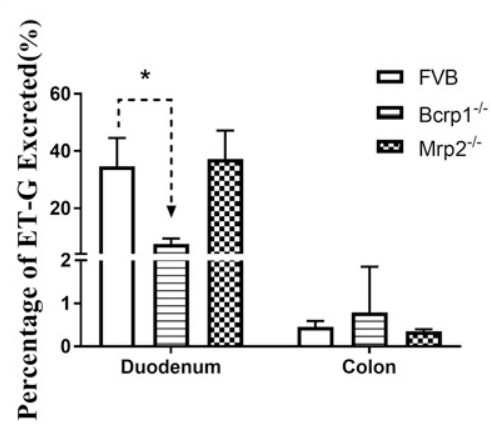

E
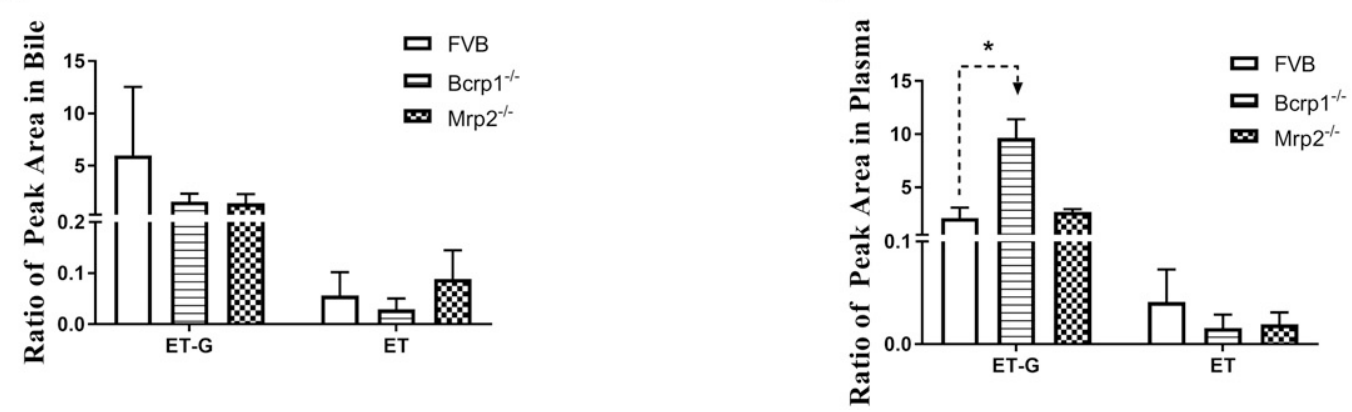

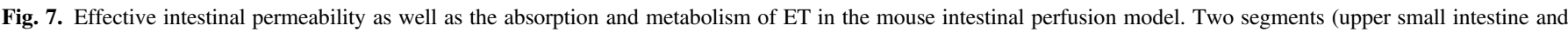

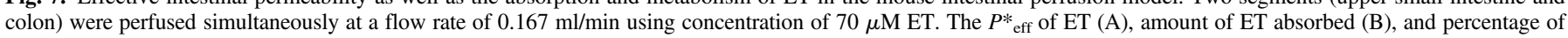

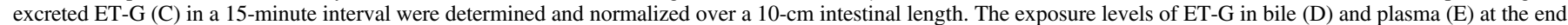

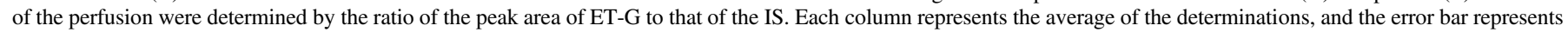

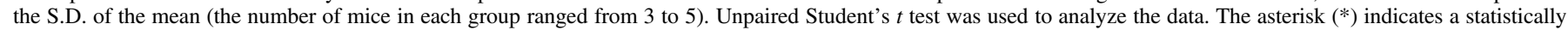
significant difference between wild-type FVB mice and knockout mice at $P<0.05$. 
A

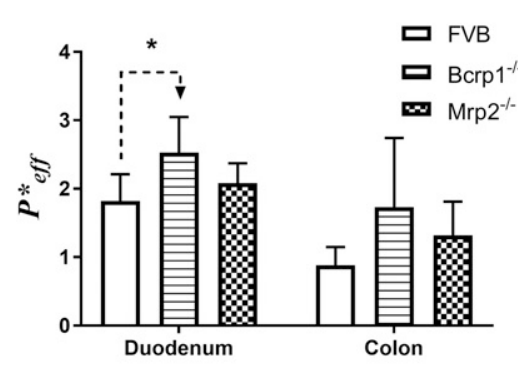

D
B

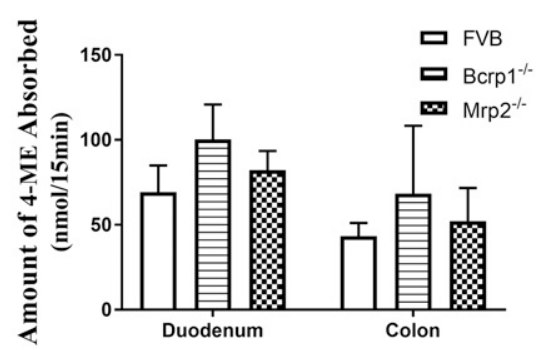

E
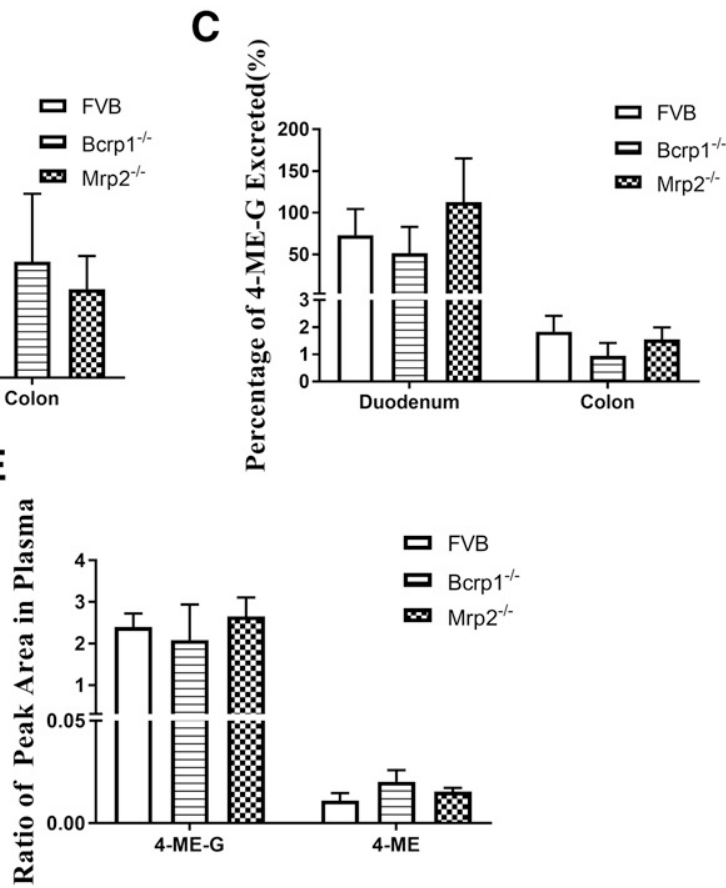

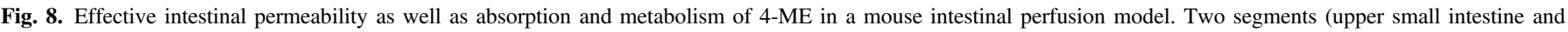

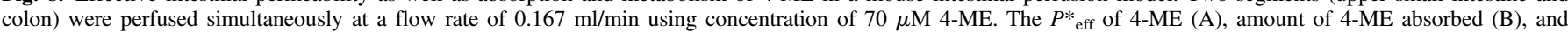

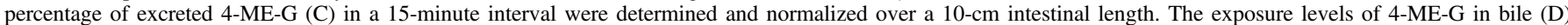

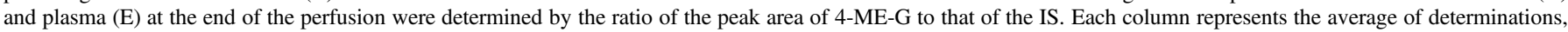

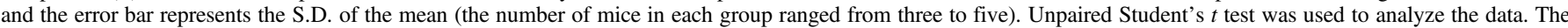
asterisk (*) indicates a statistically significant difference between wild-type FVB mice and knockout mice at $P<0.05$.

decreased the ET-G excretion into the intestine and increased the concentration of ET-G in plasma (Fig. 7, C and E). These results demonstrated that Bcrp1 plays a primary role in excreting ET-G into the intestinal lumen. The bile excretions of ET-G in the Bcrp1 ${ }^{-1-}$ and Mrp2 $2^{-1-}$ mice were markedly decreased compared with that in wildtype FVB mice, but the effect was not statistically significant (Fig. 7D). The lack of significance of these data can be explained by the large derivation. However, these results also suggested that Mrp2 is probably involved in the ET-G excretion. No significant decrease was observed for 4-ME-G intestinal and bile excretions in Bcrp1- or Mrp2-deficient mice, implying that Mrp2 compensated the functional Bcrp1 when there was a BCRP deficiency, and vice versa (Fig. 8, C and D). These results suggested that both Bcrp1 and Mrp2 had a comparable capacity in excreting 4-ME-G into the intestine and bile.

Other MRPs, including MRP3 and MRP4, that are expressed on the BL membrane of the Caco-2 cells also might be involved in the excretion of ET-G and 4-ME-G because MK571 is not a specific inhibitor of MRP2 (Gao et al., 2018). In the inhibition assays in Caco-2 monolayers, the excretion of ET-G and 4-ME-G was inhibited by MK571, which was loaded on the AP side (Fig. 4). Furthermore, MK571 showed a stronger inhibition effect on the excretion of ET-G and 4-ME-G than Ko143. These results are probably due to two reasons. First, no BCRP was expressed on the BL side in the Caco-2 cells. Second, MRP3 and MRP4, which are expressed on the BL side, were most likely inhibited by MK571. The excretion amounts of ET-G and 4-ME-G on the BL sides were higher than those of ET-G and 4-ME-G on the AP side, implying that MRPs on the BL side play a major role in excreting ET-G and 4-ME-G into the system circulation. These results could elucidate that the plasma concentrations of ET-G and 4-ME-G are higher than those of ET and 4-ME in the pharmacokinetic study. The role of MRPs on the BL membrane in ET-G and 4-ME-G excretion will be considered in a future study. In addition, MRPs were silenced by using specific small interfering RNA, or double-knockout mice could be used. Meanwhile, dosing the pure glucuronides via the i.v. route to thoroughly evaluate the disposition of the ET-G and 4-ME-G will also be conducted. Although the inhibition specificity of Ko143 and MK571 has been debated frequently, they are commonly used in screening BCRP and MRP2 substrates in in vitro assays (Sheng et al., 2015; Shi et al., 2016). These results of the inhibition assay were consistent with previous findings in which most glucuronides are substrates of BCRP and MRP2 (An and Morris, 2011; Zheng et al., 2016). Efflux transporters have been considered one of the most important factors in governing the $\overline{F \%}$ and efficacy, as well as the toxicity and drug-drug interaction susceptibility, of most market drugs and drug candidates (Li et al., 2012; Planas et al., 2012). Thus, the study of disposition characteristics of ET and 4-ME will provide valuable information for further research and development.

In the Caco-2 monolayers, the directional rates of transport of ET and 4-ME were similar (the ratio of BL-AP $P_{a p p}$ to AP-BL $P_{a p p}$ is close to 1), indicating that ET and 4-ME are most likely transported via passive diffusion in Caco-2 cells (Fig. 3A). Meanwhile, the $P^{*}$ eff values of ET and 4-ME were close to 2 (or were greater than 2 ) in the duodenum in the perfusion experiment, also suggesting that ET and 4-ME possess a good permeability (Fig. 7A; Fig. 8A). However, the $\overline{F \%}$ values of ET and 4-ME in wild-type FVB mice were $10.07 \%$ and $22.28 \%$, respectively. These results suggested that the extensive glucuronidation of ET and 4-ME resulted in their poor $\overline{F \%}$. The 4-ME-G yielded higher metabolism fractions $\left(F_{m e t}\right), J$, and $C L$ than ET-G yielded, and 4-ME-G showed lower intracellular concentrations in the absence or presence of chemical inhibitors (Figs. 3-6). These results implied that 4-ME may be more rapidly metabolized than ET in vivo.

In conclusion, this work revealed that both BCRP and MRP2 are involved in the disposition of ET-G and 4-ME-G. Compared with MRP2, BCRP exhibited a predominant transport capacity in excreting ET-G into 
the intestinal lumen. ET and 4-ME are most likely absorbed via passive diffusion, and the extensive glucuronidation resulted in their poor $\overline{F \%}$.

\section{Authorship Contributions}

Participated in research design: Li, Song, Ou, Sun, Liu, Zhu.

Conducted experiments: Song, Ou, Luo, Xie, Qi.

Contributed new reagents or analytic tools: Wang, Qi, Hu, Liu.

Performed data analysis: Song, Ou, Luo, Xie, Zhu.

Wrote or contributed to the writing of the manuscript: $\mathrm{Li}, \mathrm{Ou}, \mathrm{Zhu}$.

\section{References}

Agarwal S, Uchida Y, Mittapalli RK, Sane R, Terasaki T, and Elmquist WF (2012) Quantitative proteomics of transporter expression in brain capillary endothelial cells isolated from P-glycoprotein (P-gp), breast cancer resistance protein (Bcrp), and P-gp/Bcrp knockout mice. Drug Metab Dispos 40:1164-1169.

An $\mathrm{G}$ and Morris ME (2011) The sulfated conjugate of biochanin A is a substrate of breast cancer resistant protein (ABCG2). Biopharm Drug Dispos 32:446-457.

Chen J, Lin H, and Hu M (2003) Metabolism of flavonoids via enteric recycling: role of intestinal disposition. J Pharmacol Exp Ther 304:1228-1235.

Dai P, Zhu L, Luo F, Lu L, Li Q, Wang L, Wang Y, Wang X, Hu M, and Liu Z (2015) Triple recycling processes impact systemic and local bioavailability of orally administered flavonoids. AAPS J 17:723-736.

Gao C, Liao MZ, Han LW, Thummel KE, and Mao Q (2018) Hepatic transport of 25-hydroxyvitamin $\mathrm{D}_{3}$ conjugates: a mechanism of 25 -hydroxyvitamin $\mathrm{D}_{3}$ delivery to the intestinal tract. Drug Metab Dispos 46:581-591.

Ge S, Gao S, Yin T, and Hu M (2015) Determination of pharmacokinetics of chrysin and its conjugates in wild-type FVB and Bcrp1 knockout mice using a validated LC-MS/MS method J Agric Food Chem 63:2902-2910.

Hajime M, Shuichi Y, Makoto N, Masanori Y, Ikuko K, Atsushi K, Mutsuo S, and Keiichi T (2007) Inhibitory effect of 4-methylesculetin on hyaluronan synthesis slows the development of human pancreatic cancer in vitro and in nude mice. Int J Cancer 120:2704-2709.

Hemshekhar M, Sunitha K, Thushara RM, Sebastin Santhosh M, Shanmuga Sundaram M, Kemparaju K, and Girish KS (2013) Antiarthritic and antiinflammatory propensity of 4-methylesculetin, a coumarin derivative. Biochimie 95:1326-1335.

Hu M, Roland K, Ge L, Chen J, Li Y, Tyle P, and Roy S (1998) Determination of absorption characteristics of AG337, a novel thymidylate synthase inhibitor, using a perfused rat intestinal model. J Pharm Sci 87:886-890.

Ikeda K, Myotoku M, and Hirotani Y (2008) Characterization of multidrug resistance-associated protein mRNAs expression profiles in Caco-2 and HT-1080 cell lines induced by methotrexate. Pharmazie 63:883-889.

Jeon YJ, Jang JY, Shim JH, Myung PK, and Chae JI (2015) Esculetin, a coumarin derivative, exhibits anti-proliferative and pro-apoptotic activity in G361 human malignant melanoma. $J$ Cancer Prev 20:106-112.

Jeong EJ, Jia X, and Hu M (2005a) Disposition of formononetin via enteric recycling: metabolism and excretion in mouse intestinal perfusion and Caco-2 cell models. Mol Pharm 2:319-328.

Jeong EJ, Liu X, Jia X, Chen J, and Hu M (2005b) Coupling of conjugating enzymes and efflux transporters: impact on bioavailability and drug interactions. Curr Drug Metab 6:455-468.

Jiang H, Yu J, Zheng H, Chen J, Wu J, Qi X, Wang Y, Wang X, Hu M, Zhu L, et al. (2017) Breast cancer resistance protein and multidrug resistance protein 2 regulate the disposition of acacetin glucuronides. Pharm Res 34:1402-1415.

Klaassen CD and Lu H (2008) Xenobiotic transporters: ascribing function from gene knockout and mutation studies. Toxicol Sci 101:186-196.

Kong LL, Shen GL, Wang ZY, Zhuang XM, Xiao WB, Yuan M, Gong ZH, and Li H (2016) Inhibition of P-glycoprotein and multidrug resistance-associated protein 2 regulates the hepatobiliary excretion and plasma exposure of thienorphine and its glucuronide conjugate. Front Pharmacol 7:242.

Lee CA, O'Connor MA, Ritchie TK, Galetin A, Cook JA, Ragueneau-Majlessi I, Ellens H, Feng B, Taub ME, Paine MF, et al. (2015) Breast cancer resistance protein (ABCG2) in clinical pharmacokinetics and drug interactions: practical recommendations for clinical victim and perpetrator drug-drug interaction study design. Drug Metab Dispos 43:490-509.

Li JM, Zhang X, Wang X, Xie YC, and Kong LD (2011) Protective effects of cortex fraxini coumarines against oxonate-induced hyperuricemia and renal dysfunction in mice. Eur J Pharmacol 666:196-204.

Li Y, Lu J, and Paxton JW (2012) The role of ABC and SLC transporters in the pharmacokinetics of dietary and herbal phytochemicals and their interactions with xenobiotics. Curr Drug Metab

Ma Z, Yang X, Jiang T, Bai M, Zheng C, Zeng S, Sun D, and Jiang H (2017) Multiple SLC and ABC transporters contribute to the placental transfer of entecavir. Drug Metab Dispos 45:269-278.

Maistro EL, de Souza Marques E, Fedato RP, Tolentino F, da Silva CdeA, Tsuboy MS, Resende FA, and Varanda EA (2015) In vitro assessment of mutagenic and genotoxic effects of coumarin derivatives 6,7-dihydroxycoumarin and 4-methylesculetin. J Toxicol Environ Health A 78:109-118.

Meinl W, Ebert B, Glatt H, and Lampen A (2008) Sulfotransferase forms expressed in human intestinal Caco-2 and TC7 cells at varying stages of differentiation and role in benzo[a]pyrene metabolism. Drug Metab Dispos 36:276-283.
Ming X and Thakker DR (2010) Role of basolateral efflux transporter MRP4 in the intestinal absorption of the antiviral drug adefovir dipivoxil. Biochem Pharmacol 79:455-462.

Natarajan K, Xie Y, Nakanishi T, Beck WT, Bauer KS, and Ross DD (2011) Identification and characterization of the major alternative promoter regulating Bcrp1/Abcg2 expression in the mouse intestine. Biochim Biophys Acta 1809:295-305.

Pan L, Zeng K, Wang X, Bi H, Hu H, Huang M, Lou Y, and Zeng S (2015) Neochamaejasmin B increases the bioavailability of chamaechromone coexisting in Stellera chamaejasme L. via inhibition of MRP2 and BCRP. Int J Pharm 496:440-447.

Planas JM, Alfaras I, Colom H, and Juan ME (2012) The bioavailability and distribution of transresveratrol are constrained by ABC transporters. Arch Biochem Biophys 527:67-73.

Qin Z, Li S, Yao Z, Hong X, Wu B, Krausz KW, Gonzalez FJ, Gao H, and Yao X (2018) Chemical inhibition and stable knock-down of efflux transporters leads to reduced glucuronidation of wushanicaritin in UGT1A1-overexpressing HeLa cells: the role of breast cancer resistance protein (BCRP) and multidrug resistance-associated proteins (MRPs) in the excretion of glucuronides. Food Funct 9:1410-1423.

Sheng J, Tian X, Xu G, Wu Z, Chen C, Wang L, Pan L, Huang C, and Pan G (2015) The hepatobiliary disposition of timosaponin $\mathrm{b} 2$ is highly dependent on influx/efflux transporters but not metabolism. Drug Metab Dispos 43:63-72.

Shi J, Zheng H, Yu J, Zhu L, Yan T, Wu P, Lu L, Wang Y, Hu M, and Liu Z (2016) SGLT-1 transport and deglycosylation inside intestinal cells are key steps in the absorption and disposition of calycosin-7-O- $\beta$-d-glucoside in rats. Drug Metab Dispos 44:283-296.

Venugopala KN, Rashmi V, and Odhav B (2013) Review on natural coumarin lead compounds for their pharmacological activity. BioMed Res Int 2013:963248.

Vianna DR, Bubols G, Meirelles G, Silva BV, da Rocha A, Lanznaster M, Monserrat JM, Garcia SC, von Poser G, and Eifler-Lima VL (2012) Evaluation of the antioxidant capacity of synthesized coumarins. Int J Mol Sci 13:7260-7270.

Wang C, Pei A, Chen J, Yu H, Sun ML, Liu CF, and Xu X (2012) A natural coumarin derivative esculetin offers neuroprotection on cerebral ischemia/reperfusion injury in mice. J Neurochem 121:1007-1013.

Wang Q, Ye C, Jia R, Owen AJ, Hidalgo IJ, and Li J (2006) Inter-species comparison of 7-hydroxycoumarin glucuronidation and sulfation in liver S9 fractions. In Vitro Cell Dev Biol Anim 42:8-12.

Witaicenis A, Seito LN, and Di Stasi LC (2010) Intestinal anti-inflammatory activity of esculetin and 4-methylesculetin in the trinitrobenzenesulphonic acid model of rat colitis. Chem Bio Interact 186:211-218.

Yang G, Ge S, Singh R, Basu S, Shatzer K, Zen M, Liu J, Tu Y, Zhang C, Wei J, et al. (2017) Glucuronidation: driving factors and their impact on glucuronide disposition. Drug Metab Rev 49:105-138

Ye L, Yang X, Yang Z, Gao S, Yin T, Liu W, Wang F, Hu M, and Liu Z (2013) The role of efflux transporters on the transport of highly toxic aconitine, mesaconitine, hypaconitine, and their hydrolysates, as determined in cultured Caco- 2 and transfected MDCKII cells. Toxicol Lett 216: 86-99.

Zamek-Gliszczynski MJ, Bedwell DW, Bao JQ, and Higgins JW (2012) Characterization of SAGE Mdr1a (P-gp), Bcrp, and Mrp2 knockout rats using loperamide, paclitaxel, sulfasalazine, and carboxydichlorofluorescein pharmacokinetics. Drug Metab Dispos 40:1825-1833.

Zamek-Gliszczynski MJ, Lee CA, Poirier A, Bentz J, Chu X, Ellens H, Ishikawa T, Jamei M, Kalvass JC, Nagar S, et al.; International Transporter Consortium (2013) ITC recommendations for transporter kinetic parameter estimation and translational modeling of transport-mediated PK and DDIs in humans. Clin Pharmacol Ther 94:64-79.

Zang X, Wang G, Cai Q, Zheng X, Zhang J, Chen Q, Wu B, Zhu X, Hao H, and Zhou F (2018) A promising microtubule inhibitor deoxypodophyllotoxin exhibits better efficacy to multidrugresistant breast cancer than paclitaxel via avoiding efflux transport. Drug Metab Dispos 46: 542-551.

Zheng L, Zhu L, Zhao M, Shi J, Li Y, Yu J, Jiang H, Wu J, Tong Y, Liu Y, et al. (2016) In vivo exposure of kaempferol is driven by phase II metabolic enzymes and efflux transporters. AAPS $J$ 18:1289-1299.

Zhou S, Morris JJ, Barnes Y, Lan L, Schuetz JD, and Sorrentino BP (2002) Bcrp1 gene expression is required for normal numbers of side population stem cells in mice, and confers relative protection to mitoxantrone in hematopoietic cells in vivo. Proc Natl Acad Sci USA 99:12339-12344.

Zhu L, Lu L, Zeng S, Luo F, Dai P, Wu P, Wang Y, Liu L, Hu M, and Liu Z (2015) UDPglucuronosyltransferases $1 \mathrm{~A} 6$ and $1 \mathrm{~A} 9$ are the major isozymes responsible for the 7-Oglucuronidation of esculetin and 4-methylesculetin in human liver microsomes. Drug Metab Dispos 43:977-983.

Zimmermann C, van de Wetering K, van de Steeg E, Wagenaar E, Vens C, and Schinkel AH (2008) Species-dependent transport and modulation properties of human and mouse multidrug resistance protein 2 (MRP2/Mrp2, ABCC2/Abcc2). Drug Metab Dispos 36:631-640.

Address correspondence to: Dr. Lijun Zhu, Joint Laboratory for Translational Cancer Research of Chinese Medicine of the Ministry of Education of the People's Republic of China, International Institute for Translational Chinese Medicine, Guangzhou, Guangdong, 510006, PR China. E-mail: zhulijun@gzucm.edu.cn; or Dr. Zhongqiu Liu, Joint Laboratory for Translational Cancer Research of Chinese Medicine of the Ministry of Education of the People's Republic of China, International Institute for Translational Chinese Medicine, Guangzhou, Guangdong, 510006, PR China. E-mail: liuzq@gzucm.edu.cn 